\title{
Expanding workplace HIV/AIDS prevention activities for a highly mobile population: Construction workers in Ho Chi Minh City
}

Vu Ngoc Bao

Philip Guest

Julie Pulerwitz

Le Thuy Lan Thao

Duong Xuan Dinh

See next page for additional authors

Follow this and additional works at: https://knowledgecommons.popcouncil.org/departments_sbsr-hiv How does access to this work benefit you? Let us know!

\section{Recommended Citation}

Vu Ngoc Bao, Philip Guest, Julie Pulerwitz, Le Thuy Lan Thao, Duong Xuan Dinh, Tran Thi Kim Xuyen, and Ann Levin. 2003. "Expanding workplace HIV/AIDS prevention activities for a highly mobile population: Construction workers in Ho Chi Minh City," Horizons project report. Washington, DC: Population Council. 


\section{Authors}

Vu Ngoc Bao, Philip Guest, Julie Pulerwitz, Le Thuy Lan Thao, Duong Xuan Dinh, Tran Thi Kim Xuyen, and Ann Levin 


\section{Hprizons}

Expanding Workplace HIV/AIDS

Prevention Activities for a Highly Mobile Population:

Construction Workers in

Ho Chi Minh City

Ho Chi Minh City AIDS Committee

Ho Chi Minh City Labor Union

College of Social Sciences and Humanities of

HCMC National University

Population Council

Horizons Program 


\section{Expanding Workplace HIV/AIDS \\ Prevention Activities for a Highly Mobile Population: Construction Workers in Ho Chi Minh City}

Dr. Vu Ngoc Bao, formerly of the Population Council/Vietnam ${ }^{1}$

Dr. Philip Guest, Horizons/Population Council

Dr. Julie Pulerwitz, Horizons/PATH

Dr. Le Thuy Lan Thao, Ho Chi Minh City AIDS Committee

Mr. Duong Xuan Dinh, Ho Chi Minh City Labor Union

Dr. Tran Thi Kim Xuyen, College of Social Sciences and Humanities of

HCMC National University

Dr. Ann Levin, Horizons/FHI

${ }^{1}$ Dr Bao is now with Family Health International 


\section{Acknowledgments}

The Horizons authors would like to thank the research partners on the project, including the Population Council/Vietnam and the College of Social Sciences and Humanities of the Ho Chi Minh City (HCMC) National University. Also, thanks to the HCMC AIDS Committee, especially Dr. Le Truong Giang and Dr. Le Thuy Lan Thao; staff at the HCMC Labor Union, Social Work Center, especially Mr. Duong Xuan Dinh and Mrs. Nguyen Thi Hue; and the peer educators and health communicators who were so committed to the implementation of the programs.

Thanks to the team of people who helped develop the program materials, including consultant Jamie Uhrig, Dr. Anthony Pramualratana of the Thailand Business Coalition on AIDS, consultant Mr. Do Van Binh, Dr. Truong Trong Hoang of the Health Information and Education Center, Dr. Tran Thinh from the HCMC AIDS Committee, and representatives of the labor union. Many thanks as well to the construction companies who permitted and supported the implementation of these programs, and to the workers themselves, who permitted us to ask questions. The authors would like to acknowledge the Ford Foundation for its financial support of the intervention and Dr. Lisa Messersmith of the Ford Foundation for her suggestions for improving the peer education program.

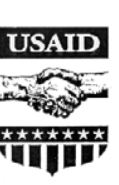

This study was supported by the Horizons Program, which is implemented by the Population Council in collaboration with the International Center for Research on Women, International HIV/AIDS Alliance, Program for Appropriate Technology in Health, Tulane University, Family Health International, and Johns Hopkins University. Horizons is funded by the U.S. Agency for International Development, under the terms of HRN-A-00-97-00012-00. The opinions expressed herein are those of the authors and do not necessarily reflect the views of the U.S. Agency for International Development.

Published in August 2003.

\footnotetext{
(1) Population Council

The Population Council is an international, nonprofit, nongovernmental institution that seeks to improve the wellbeing and reproductive health of current and future generations around the world and to help achieve a humane, equitable, and sustainable balance between people and resources. The Council conducts biomedical, social science, and public health research and helps build research capacities in developing countries. Established in 1952, the Council is governed by an international board of trustees. Its New York headquarters supports a global network of regional and country offices.
}

Copyright (C) 2003 The Population Council Inc. 


\section{Table of Contents}

Executive Summary

Introduction $\quad 5$

$\begin{array}{lc}\text { Mobility and HIV risk and prevention } & 6\end{array}$

$\begin{array}{ll}\text { Vietnamese context } & 6\end{array}$

$\begin{array}{lr}\text { Intervention Activities } & 8\end{array}$

Health communicator program $\quad 8$

Peer education and management motivation program 9

Research Methods 11

$\begin{array}{ll}\text { Research design and site selection } & 11\end{array}$

$\begin{array}{ll}\text { Data collection and analysis } & 12\end{array}$

$\begin{array}{ll}\text { Results } & 16\end{array}$

$\begin{array}{ll}\text { Workers } & 16\end{array}$

Peer educators and health communicators $\quad 25$

Management motivation $\quad 31$

$\begin{array}{ll}\text { Cost analysis } & 35\end{array}$

Dissemination Workshop and Future Plans 41

Conclusions and Recommendations 43

$\begin{array}{ll}\text { References } & 45\end{array}$ 


\section{Executive Summary}

The HIV epidemic in Vietnam is growing, and promotion of prevention behavior among vulnerable populations, such as migrant workers, is becoming increasingly critical. In Ho Chi Minh City (HCMC), the locus of the epidemic in Vietnam, efforts have been under way for several years to implement prevention efforts for migrant worker populations. Led by the HCMC AIDS Committee and HCMC Labor Union, the main activity has utilized volunteer health communicators (HC) to visit workplaces and conduct HIV education activities. However, these efforts have reached only a relatively small number of the intended audience, and the impact of the current program is unclear. Local authorities want to scale up their efforts but require information on the most effective and least costly activities, as well as their potential for scale up.

The Horizons Program, in conjunction with the Population Council/Vietnam, the HCMC Labor Union, the HCMC AIDS Committee, and the College of Social Sciences and Humanities of HCMC National University, with additional support from the Ford Foundation, compared two programs for highly mobile construction workers: the existing $\mathrm{HC}$ workplace program, which utilizes mostly social work students to deliver HIV prevention education, and a new peer education program.

The HC program has several positive characteristics, including minimal costs for implementation and a large supply of motivated and knowledgeable educators. However, there were concerns about the substantial turnover of health communicators and whether social work students, about half of whom are female, are the most effective HIV prevention educators for a largely male construction worker population. The new program uses construction worker peer educators (PEs) to promote HIV risk reduction and fosters management involvement and support for the workplace program. While peer education programs have been found to be effective in many settings, local authorities were concerned about whether construction workers could be capable educators, and whether they could be motivated to stick with the program. Both PEs and HCs received training in HIV/STI risk and prevention information, group facilitation skills, and one-on-one non-formal counseling.

This operations research study compares the feasibility, impact, and cost of the two programs. Other important objectives of the study include exploring the role of the labor union in managing workplace HIV/AIDS programs, examining strategies to motivate management to support HIV/AIDS workplace programs in relatively low-prevalence environments, and demonstrating that a workplace program can successfully follow a highly mobile work force though the use of peer educators.

The research consists of an experimental design with two intervention arms and multiple rounds of data collection. Twenty-three construction sites were selected after a mapping exercise of construction sites that met certain criteria in 19 of 22 districts across Ho Chi Minh City. They were randomly assigned to the peer educator or health communicator intervention. Six sites each (a total of 12) initially implemented the intervention. The number of sites expanded as peer educators completed their work and moved on to new work sites; new sites were also added in the health 


\section{Hgrizons}

communicator arm for purposes of comparability. Permission from management was sought at each new work site.

The research included a formative phase to help develop the intervention activities. During the evaluation phase, a combination of qualitative and quantitative research methodologies was used to assess the process, cost, and impact of the different interventions. Monitoring forms were collected weekly from PEs and after each visit from HCs. Detailed information on indirect and direct costs was kept throughout the project. All active peer educators and health communicators were surveyed at baseline ( $\mathrm{n}=68$ PEs and $69 \mathrm{HCs}$, respectively), six months ( $\mathrm{n}=56$ and 46, respectively) and 12 months ( $n=45$ and 45 , respectively). Surveys were conducted with construction workers before the intervention, and six and twelve months later. A baseline survey was administered to all workers (i.e., a census sample) in each of the PE $(n=742)$ and HC $(n=$ 502) sites. During the follow-up period the number of exposed workers increased, as PE sites increased to 15 due to the movement of PEs to new sites when their work was complete, and an additional 6 health communicator sites were selected. As a result, a sample instead of a census of workers was selected for the second ( $\mathrm{n}=751 \mathrm{PE}$ sites and $505 \mathrm{HC}$ sites, respectively) and third rounds ( $\mathrm{n}=363 \mathrm{PE}$ sites and $211 \mathrm{HC}$ sites, respectively). Focus group discussions and in-depth interviews were also held with company managers, peer educators and health communicators, workers, and labor union staff.

\section{Key Findings}

PEs contacted more workers and were better at distributing condoms than HCs. Among workers surveyed, a higher proportion of workers at PE sites had contact with the intervention than did workers at the HC sites. At six months follow-up, 73 percent of workers at PE sites and 57 percent at $\mathrm{HC}$ sites had direct experience with program activities. At 12 months follow-up, the figures were 61 percent and 45 percent, respectively. The PEs were also more successful in distributing condoms to fellow workers than the HCs. At six months, 88 percent of workers at PE sites who had contact with PEs reported that they had received condoms from them, compared to 76 percent of workers who had contact with $\mathrm{HCs}(\mathrm{p}<.01)$. At 12 months, 78 percent of workers at $\mathrm{PE}$ sites and 65 percent of workers at $\mathrm{HC}$ sites reported the same $(\mathrm{p}<.01)$. Qualitative data suggest that workers were more comfortable getting condoms from PEs.

\footnotetext{
Although turnover among both groups was a problem, PEs had better retention rates than $\mathrm{HCs}$, and PEs were successful in continuing program activities at new work sites. An ongoing concern has been the high level of dropouts from the HC programs and the need to keep recruiting and training new HCs. However, there was also a concern that many PEs would be lost when they moved to new work sites. The results indicate that there was significant turnover with both groups, although the turnover was greater among HCs than PEs. Approximately two-thirds of the PEs who started the program remained after six months, compared to 55 percent of the HCs. At 12 months, 52 percent of the PEs remained, compared to 43 percent of the HCs. Peer educators often continued their activities when they moved to new sites.
} 
PEs' comfort levels in discussing sexual topics and knowledge about HIV/STI greatly improved over time and equaled or surpassed those of HCs at follow-up. At baseline, HCs were significantly more comfortable discussing topics related to sexual behavior than were PEs $(\mathrm{p}<.001)$. After six months, PEs who remained in the program were more comfortable discussing sensitive topics with workers than were HCs. This gap widened further after one year. At baseline, levels of knowledge were higher among HCs than PEs $(\mathrm{p}<.05)$. This difference disappeared by the second round of data collection. Equivalent levels of knowledge were also found after one year.

Support of management was key, and management became involved for varied reasons. An important part of the PE program was involving company management, since PE programs require permission from authorities to train their workers and to allow them time to engage in PE activities. Interviews with program coordinators indicate that the most successful way to motivate management was to work with both top management and site management. Findings from construction company managers indicate that their support of workplace HIV/AIDS programs was motivated by multiple factors. These range from concerns about the wellbeing of their workers to the desire to reduce stigma in the workplace. Having a reputable organization like the labor union address concerns about costs and time spent on the intervention appears to have been an important part of a successful strategy to get management on board.

In both intervention arms, workers' HIV/STI knowledge, life skills and condom efficacy, and risk perception increased, and stigmatizing attitudes decreased. However, changes were greater at PE sites. Sexual norms in support of HIV risk reduction increased only at PE sites. There were statistically significant improvements in key impact variables among workers at PE sites between baseline and six months after the program was initiated. For workers exposed to the HC program, changes between baseline and six months later were also statistically significant, with the exception of an index that measured sexual norms supporting HIV risk reduction. However, after controlling for differences in the sociodemographic composition of workers, the net effects of positive changes at the PE sites were significantly greater for several variables than at the $\mathrm{HC}$ sites, including knowledge and reduction in stigmatizing attitudes.

Diffusion of information to non-exposed workers appears greater at the PE sites than the HC sites. HIV/STI knowledge also increased significantly for workers at the PE sites who did not have direct exposure to activities with PEs, but this increase was not found among workers in the HC sites who were not directly exposed to HCs. This is likely a result of increased communication about HIV/AIDS between exposed and unexposed workers at the PE sites.

There is some evidence of increased condom use, although workers report low levels of sexual risk behavior. Reported sexual risk behavior in the surveys was quite low in this population, so conclusions about the impact of the programs on sexual risk behavior are limited. There is evidence - such as an increase of condom use with a non-marital sexual partner - that suggests an impact in that area. Furthermore, the qualitative data suggest that workers engaged in substantially more HIV risk behavior than was found in the close-ended surveys. Qualitative evidence supports substantial reductions in risk behavior and increases in safe sex practices, particularly among workers exposed to the peer education intervention. 


\section{Hgrizons}

Cost per worker reached was lower for the PE program than the $\mathrm{HC}$ program. The overall start-up and operating costs were greater for the PE program than the HC program over one year. The total cost for the PE program was 235 million dong (US\$15,678) and for the HC program was 187 million dong (US\$12,455). However, the productivity analysis shows that the cost per worker reached was lower for the PE program than the HC program. The cost per worker for the PE program was 470 thousand dong (US\$31.36) and for the HC program was 561 thousand dong (US\$37.40); a 12 percent lower cost per worker. The estimated cost of replicating the peer education program in an additional six sites is 163 million dong (US\$12,648), but costs to the program would be US $\$ 11,991$. 


\section{Introduction}

As HIV prevalence in Vietnam increases, promoting prevention behavior among vulnerable populations, such as migrant workers, becomes more critical. In Ho Chi Minh City (HCMC), the epicenter of the epidemic in Vietnam, efforts by the local government have been in place for several years to focus prevention activities on migrant workers. The principal activity uses volunteer health communicators (HCs) to conduct HIV education activities at workplaces. Yet these prevention efforts have reached only a minority of migrant workers, and the effectiveness of the approach remains unclear. Local authorities want to expand their efforts but need more information about which activities are the most effective and least costly.

The Horizons Program, in conjunction with the Population Council/Vietnam, the HCMC Labor Union, the HCMC AIDS Committee, and the College of Social Sciences and Humanities of HCMC National University, with additional support from the Ford Foundation, compared the existing workplace HIV prevention program for highly mobile construction workers with a new peer education program. The existing program utilizes visiting health communicators, who are social work students, for HIV prevention education. This program has a number of positive characteristics, including minimal costs for implementing the program and a large supply of motivated and knowledgeable educators. However, there were concerns about the substantial turnover of health communicators and whether social work students, about half of whom are female, are the most effective HIV prevention educators for a largely male construction worker population.

The new program uses construction worker peer educators (PEs) to promote HIV risk reduction and fosters management involvement and support for the workplace program. While peer education programs have been found to be effective in many settings, local authorities were concerned about whether construction workers could be capable educators and whether they could be motivated to stick with the program. Both peer educators and health communicators received training in HIV/STI risk and prevention information, group facilitation skills, and one-on-one non-formal counseling.

The main objectives of this operations research study were to:

- Compare the feasibility, impact, and costs of two different workplace-based HIV/AIDS prevention programs for a mobile construction worker population.

- Examine strategies to motivate management to support HIV/AIDS workplace programs in relatively low-prevalence environments.

- Explore the role of the labor union in facilitating and coordinating workplace HIV/AIDS programs. 


\section{Hgrizons}

- Determine whether a peer education program can successfully move with a highly mobile work force and continue education activities, since peer educators are part of the work force.

\section{Mobility and HIV Risk and Prevention}

Mobile populations have long been recognized as important links in the geographic spread of HIV. Throughout Africa and Asia, highly mobile populations such as truck drivers have been the focus of HIV prevention efforts. The main rationale for focusing on these groups is that the social context associated with their employment increases the likelihood of their engagement in high-risk behavior and hence exposes them to an increased risk of contracting HIV. At the same time they can serve as a link in spreading HIV into dispersed populations.

Apart from transport workers and traders, who are constantly on the move, little attention has been paid to migrant populations away from home for long periods of time but not constantly on the move, a segment of the labor force that is growing in most developing countries. Such workers typically enter low-paid occupations that have little job security, such as construction and domestic service.

Prevention efforts targeting migrants can be challenging to implement, since they can be difficult to identify and general prevention messages often do not resonate for them. One approach is to provide information at the workplace. Migrants are typically concentrated in a few occupations, which makes it possible to focus HIV/AIDS prevention efforts at workplaces and thus reach large numbers of migrants. However, most workplace education approaches have targeted stable work forces, such as factory workers. Much less work has been undertaken with mobile work populations. One enduring problem in reaching a mobile population is that when workers move on, a workplace-based program no longer reaches its target audience. This study tests two different strategies to reach mobile construction workers.

\section{Vietnamese Context}

As of 31 December 2002, 59,200 cases of HIV infection had been reported in Vietnam's 61 provinces. Of the total, one-fifth of these cases were reported in Ho Chi Minh City (National AIDS Standing Bureau 2002), where heterosexual intercourse is a significant and growing mode of transmission (Chung et al. 1998). There are rapidly rising HIV prevalence rates among sex workers in Ho Chi Minh City and among men who receive services from STI clinics (National AIDS Standing Bureau 2001). The National AIDS Committee (NAC) of Vietnam has identified mobile populations as important target groups for HIV prevention activities (National AIDS Standing Bureau 2001).

In Vietnam, there is increasing movement of population from rural to urban areas in search of employment, since economic development is concentrated in urban areas. Migrant workers in $\mathrm{HCMC}$ are typically young people who migrate from rural areas to the city to earn a living. Female migrants mainly work in the textile and food processing industry, while male migrants mainly work 
in construction or manufacturing industries, or in services (Hoa and Tham 1999). Because of the city's booming economy, there are many construction sites throughout the city. Based on information received from the Department of Statistics of Ho Chi Minh City, the HCMC AIDS Committee believes that construction sites in the city currently employ approximately 160,000 temporary workers (HCMC AIDS Committee, 2002, personal communication).

Migrants may be at particular risk of contracting HIV because they are away from home, may have multiple sex partners, and typically do not have access to sexual and reproductive health information and services. A Behavioral Surveillance Survey (BSS) was conducted by FHI in 2000, in which 506 construction workers in HCMC were interviewed. The BSS found that a typical construction worker was single, male, young (mean age of 29 years old), had six to nine years of schooling, and had lived in the city for less than one year (Chung and Kane 2001). These workers reported behaviors that could make them vulnerable to HIV, including sex with multiple sexual partners and inconsistent condom use with sex workers and occasional partners. For example, more than a fourth of workers did not use a condom at last sex with a sex worker, and more than half did not report condom use at last sex with an occasional partner. 


\section{Hgrizons}

\section{Intervention Activities}

\section{Health Communicator Program}

In 1998, the Ho Chi Minh City Labor Union, with financial support from the HCMC AIDS Committee, initiated a project designed to increase HIV/AIDS knowledge and preventive behaviors among construction workers and other mobile groups in the city. The program uses volunteer health communicators (HCs) to visit mobile workers at their work sites and provide educational materials and condoms to workers. The labor union viewed the health communicator approach as advantageous because HCs are easy to recruit and train, are motivated and knowledgeable, and require little investment.

However, there has been a very high dropout rate among HCs, which results in the frequent training of new recruits. Because most HCs are students, it has been difficult to maintain their involvement and interest after they graduate. Furthermore, since most HCs are female, it is unclear whether female social work students are the most effective HIV prevention educators for a largely male construction worker population. Because of these limitations, the labor union and AIDS Committee expressed an interest in developing and implementing an alternative workplace HIV/AIDS prevention intervention (described below), and testing the feasibility, cost, and effectiveness of both programs.

Health communicators work part-time and receive a small allowance of 10,000 to 20,000 dong (70 cents to \$1.35) per worksite visit, largely for transportation costs. HCs hear about the program through newspapers, the university's Youth Union, or their friends, and voluntarily register to participate. Volunteer health communication teams visit mobile construction workers at their work sites and provide information to workers either in groups or in one-on-one sessions. They distribute leaflets, which were developed and provided by the Ho Chi Minh City AIDS Committee, discuss the leaflets with the workers, and distribute condoms when requested. The health communicators visit sites approximately once or twice a week. Each $\mathrm{HC}$ visits three to five sites per week and spends approximately one to one-and-half hours per visit to construction sites, including travel. In most cases, the health communicators approach workers during breaks off-site, such as during

lunchtime, because safety rules prevent them from entering most sites. Management is not actively involved in the program.

During the study period, the HCs received both initial training and refresher trainings. These included a three-day initial training session, followed by one day in the fourth month of the intervention and another day in the eighth month of the intervention. Training encompassed HIV/AIDS transmission and prevention, including condom use and partner reduction; STI symptoms and treatment; interpersonal communication skills; negotiating skills; laws related to HIV/AIDS and drug use prevention and control; roles and responsibilities of health communicators; and record keeping and monitoring systems. The contents of the sessions were copied and provided to the HCs for their reference. 
Because of dropouts - almost 50 percent had dropped out by the end of the fourth month of the intervention study period - the labor union recruited and trained additional HCs, and also reactivated communicators who used to work for previous projects. During the course of the oneyear intervention, 109 health communicators took part in the project.

Members of the labor union acted as liaisons for the project. Two labor union officials were trained as health communicator coordinators. Training included how to conduct HIV/AIDS update sessions with health communicators, and maintaining appropriate record keeping and monitoring systems.

\section{Peer Education and Management Motivation Program}

Peer educators were recruited from among the workers themselves, at a ratio of approximately one peer educator per 20 workers per site. Companies were provided with criteria for selection of PEs, who should (1) be team leaders or key workers, (2) be respected persons in the team, (3) have an education level of at least basic secondary school, (4) have an interest in helping workers, and (5) have good communication skills. At the request of construction company management, the selection of PEs was determined at each site.

The great majority of PEs were male construction workers, but some female PEs were employed to reach female workers. The peer educators targeted workers of the same sex. They were provided with small incentives of 150,000 dong (about \$10) per month. While peer education programs have been found to be effective in many settings, local authorities wondered whether construction workers could be capable educators and could be motivated to stick with the program, and were therefore interested in comparing the impact of the two programs.

Peer educators received both initial and refresher training. They participated in an initial four-day training course, followed by a two-day training session in the fourth month of the intervention and a one-day training session in the eighth month of the intervention. Training encompassed HIV/AIDS transmission, symptoms, effects, and prevention; principles of health education, behavior change, and decision making; peer discussion facilitation and interpersonal communication; participatory outreach approaches; roles and responsibilities of peer educators; and recordkeeping and monitoring systems. Peer education workshops utilized participatory approaches, including role-plays, brainstorming, group discussions, educational games, and drama and songs.

As part of their work, the peer educators gave presentations to large groups, held small interactive group discussions, and conducted informal one-on-one counseling sessions with their fellow workers. PEs discussed HIV/AIDS and such safer sex practices as condom use and partner reduction; facilitated decision-making and life skills related to HIV risk reduction; answered questions; discussed fears and stigma related to HIV; distributed pamphlets, condoms, and other materials; provided information about the availability of STI services; and generally tried to foster an environment of greater awareness and understanding about the disease. Condoms were also 


\section{Hgrizons}

made available from boxes in accessible areas of each site so that construction workers could freely take them.

Peer coordinators, who were members of the labor union, acted as liaisons for the project. Three union officials were trained as peer coordinators. Training included how to conduct HIV/AIDS update sessions with peer educators and how to maintain appropriate recordkeeping and monitoring systems.

Because some PEs dropped out and some construction sites were expanded to new locations, the labor union continued to recruit and train peer educators. Before the intervention study began, 68 PEs were recruited and trained. After the first six months, 48 remained in the program, so the labor union recruited and trained an additional 23 peer educators. Because this population is mobile, with workers moving between sites when they finish their phase of work, PEs who left the work site were encouraged to continue their activities at the next site.

Key aspects of the PE program were derived from Social Cognitive Theory, which emphasizes the importance of modeling behaviors with peers and developing the confidence to enact a behavior (i.e., self-efficacy) through skills-building (Bandura 1986). A needs assessment was also undertaken with workers and management to identify the issues that construction workers felt should be addressed in the program. In addition, the program drew on existing workplace peer education manuals, such as "Friends to Friends" (Chaiyapet 1996), designed for blue- and whitecollar workers in Thailand. A publication entitled "A training manual on HIV/AIDS peer education for construction workers" was produced and published in Vietnamese. This manual was used to train peer educators and was distributed to them for their reference.

To facilitate the operation of the PE program, labor union officials worked to motivate management to commit themselves to the workplace program, sponsoring motivational meetings and distributing informational materials to managers both on-site and in the upper levels of management. The presentations were designed to raise managers' awareness of the impact of HIV/AIDS on the private sector and show how managers can protect profits and productivity with prevention programs and policies. At the beginning of the project, labor union officials approached companies to recruit them into the project. After companies agreed to implement the program at specific work sites, the union continued to liaise with site managers to keep them updated about peer education activities.

To help prepare them for these tasks, union officials participated in a two-day training session on how to motivate management acceptance of and involvement in AIDS workplace programs. The training materials drew upon a needs assessment with managers and also upon existing materials, including materials from the Thailand Business Coalition on AIDS (TBCA). A manual on motivating construction companies to participate in workplace HIV/AIDS programs was developed and published in Vietnamese to instruct project officers in the recruitment process. 


\section{Research Methods}

\section{Research Design and Site Selection}

The research consists of an experimental design, with two intervention arms and three rounds of data collection with cross-sectional samples. Construction sites were randomly assigned to the peer education or health communication intervention. To select construction sites for the study, the labor union conducted a mapping exercise in 19 districts (17 urban districts and two suburban districts) of the 22 districts in Ho Chi Minh City. Every construction site with more than 50 workers was included in the database, which resulted in 50 eligible sites involving 47 companies. Using such criteria as length of expected time to completion of construction work and selection of only one site per construction company, researchers identified 23 sites. The sites were then randomly assigned to the PE group or HC group. The order of contact within each of the groups was then randomly assigned.

From the list of 12 assigned PE sites, the labor union contacted all of the construction companies; six (50 percent) agreed to participate. Specifically, the labor union obtained permission from six to give a formal presentation to management on the proposed peer education project, all of which agreed to participate in the intervention research. The other six companies did not participate either because they (1) did not agree to a meeting to discuss the details of the proposed program, (2) were not appropriate for the study since their construction site was about to be completed, or (3) the head office was based in Hanoi instead of HCMC and the appropriate decision-makers were not reached. Therefore, even though sites were randomly distributed to the two arms at the start of the study, because six of the 12 sites contacted for participation in the peer education program agreed to participate, they may therefore be different than the other six sites. Over one year, PEs from the six sites that agreed to participate were followed, and if they moved to new workplaces, managers at the new sites were contacted and the intervention continued. The number of sites expanded as peer educators completed their work and moved on to new worksites.

From the list of 11 assigned HC sites, the first six were contacted. This process was consistent with protocols that had been used previously in the HC program. All six agreed to participate. The high response rate was likely due to the fact that the request was simple: permission to speak to the workers outside of the construction sites, outside of work hours. After six months, all of the originally selected $\mathrm{HC}$ health sites had closed, so for purposes of comparability, six more HC sites were selected for the final round of program activities and data collection. These sites were selected based on ease of travel for health communicators to the site locations, and permission was again sought from managers at each site. 


\section{Hgrizons}

\section{Data Collection and Analysis}

The research included a formative phase to help develop the intervention activities and an evaluation phase to assess the impact of the two programs.

\section{Formative phase}

The objectives of the formative research were: (1) to obtain the information necessary to develop the peer education approach to be employed in the study, and (2) to identify procedures and materials that can be used to obtain the active participation and support of HIV workplace programs by construction company management.

Formative research was carried out at nine construction sites. The research team conducted semistructured interviews with 11 workers, ten site managers, ten company managers, and three wives of the workers, and undertook focus group discussions (FGDs) with three groups of workers, two groups of site managers, and one group of workers' relatives. The interviews with workers, which were conducted after working hours and took approximately 40 to 60 minutes to complete, explored their interaction patterns and behavioral influences, examined needs and access to services, and investigated their risk behaviors. The interviews with managers, which were carried out after appointments had been made, obtained information about the work patterns on a site, existing services for workers, and company policies on HIV/AIDS, and also explored how the managers perceived the need for a workplace HIV/AIDS program and what workplace programs were operating.

The FGDs with workers, managers, and wives of workers were conducted for between 45 and 60 minutes and covered a variety of topics. For example, the FGDs with workers explored work situations and ideas about how a workplace program can be implemented, and investigated types of risk behaviors and values that sustain those types of behaviors. The FGDs with managers focused on obtaining an understanding of the perceived need and acceptance of managers for a workplace HIV/AIDS program, exploring how they see such a program working and assessing the sustainability of the program. The FGDs with wives of workers obtained an understanding of the family situation of married male workers, and explored how wives perceive the influence of peers and the risk behaviors of their husbands. The team also conducted extensive observations at three construction sites. Participatory learning and action (PLA) sessions were carried out at two construction sites. Observations at construction sites helped researchers gain an understanding of the work and interaction patterns of workers.

\section{Evaluation phase}

During the evaluation phase, researchers used a combination of qualitative and quantitative research methodologies to assess the process, cost, and impact of the different interventions (see Table 1 for summary of data collection techniques). PEs and HCs regularly submitted monitoring forms about their program activities. At baseline, the research team interviewed all 68 PEs and 69 
HCs who attended the initial training courses. Six and twelve months later, the research team interviewed currently working PEs ( $\mathrm{n}=56$ and 46, respectively) and HCs ( $\mathrm{n}=45$ and 45, respectively). Two FGDs each were also held with PEs and HCs who had been involved with the project for the full year. Interviews were also undertaken with labor union staff who were the coordinators of the two programs, as well as company management $(n=17)$.

The research team conducted cross-sectional surveys of construction workers before the intervention, and six and twelve months later. A baseline survey was administered to all workers (i.e., a census sample) in each of the PE $(n=742)$ and HC $(n=502)$ sites. The response rate was almost 100 percent. During the follow-up period, the number of PE sites increased to 15 due to the movement of PEs to new sites when their work was complete; six new HC sites were added for comparison purposes. As a result, the total number of workers being reached by the interventions had greatly increased, and the research team conducted a two-stage sampling of workers for the second and third survey rounds.

The first stage was based on respective proportions in the baseline survey; the second used a systematic random sampling strategy. At six months, the research team interviewed 751 workers from PE sites and 505 from HC sites. The number of workers estimated to be at construction sites with PEs and HCs after 12 months were 790 and 740 workers. To continue to follow PEs to new sites and to examine the impact of the program on new groups of workers, researchers conducted a final survey at 12 months with 363 workers from the 13 PE sites that remained and with 211 workers from the six HC sites that had been added.

In-depth interviews (IDIs) were also held with ten construction workers from each of the two arms after 12 months of the intervention. The IDIs with workers, which were administered at construction sites after working hours, took between 40 and 60 minutes to complete. Their purpose was to explore workers' level of contact with PEs or HCs, obtain their perceptions of the intervention and suggestions for improving the program, and examine their behavior change for HIV prevention.

Surveys administered to educators and workers contained a number of topics, including HIV and STI knowledge and attitudes, sexual norms, condom self-efficacy, life skills and HIV risk-related decision-making, HIV-related stigma, risk perception, and HIV risk and prevention behaviors. Most variables were measured by one questionnaire item, but a number of indices were also generated. Eight true or false questions were used to construct an additive summary index of knowledge of HIV/AIDS (e.g., "Can a person who looks healthy be infected with HIV?"). Fifteen questionnaire items that probed issues related to norms in the context of sexual relationships were used to create an additive index of sexual norms. Each item asked for a response regarding whether a particular situation was acceptable. The following are two examples: "A young man is single and likes to have sex with sex workers" and "A female worker regularly carries condoms in her purse." Each item was coded 0 where the response indicated that the worker ascribed to a norm that could lead to increased vulnerability to contracting HIV and 1 if they did not ascribe to that norm (or ascribed to a norm that would support preventive behaviors). The maximum score on the index was 15 and the minimum score was 0 (Cronbach's alpha of 0.55 ). 


\section{Hgrizons}

Life skills were measured by providing respondents with seven hypothetical situations and asking them to express, on a scale of 1 to 10 , how confident they would be in each situation in making a specified decision. An example of one of the situations is as follows: "You are going out with someone and you like each other very much. Your partner wants to have sex without a condom. If you want to use a condom, how confident are you that you could ask him or her to use one?" The index was created by adding the individual responses for each item and then dividing by 7 .

Therefore, the final index can range from one to ten and reflects the underlying scale of each item. If a respondent was completely confident in making the decision in all seven situations, he or she would obtain a score of 10 . The measure of reliability of the index used, Cronbach's alpha, was high at 0.79 , suggesting that the seven items used are measuring one underlying construct.

In addition to life skills in general, an additive index was constructed to measure the extent to which workers felt confident in specifically using a condom. The index was constructed from two items, each of which was scored one to four, with increasing values reflecting greater comfort/confidence related to condom use: confidence in obtaining a condom and confidence in using a condom. The index has a range of one to four, reflecting the distribution on the two items that comprise the index (Cronbach's alpha for the constructed index was 0.69, indicating that the index is reliable).

An index of stigmatizing attitudes was constructed from five items taken from widely used surveys, including the DHS. Examples of the items are as follows: "If you knew that a co-worker had HIV/AIDS, would you be willing to work with him/her in the same place?" and "If you knew that a shopkeeper or food seller had the AIDS virus, would you buy vegetables from them?" Each of the five items was coded as 0 (no stigmatizing attitude) and 1 (stigmatizing attitude). The index, which had a Cronbach's alpha of 0.79 , was constructed by summing up responses from the five items and then dividing by 5 . The resulting measure can therefore be interpreted as the proportion of the five items in which a stigmatizing attitude was reflected. A reduction in the index value reflects a reduction in stigma.

Surveys administered to educators also contained questions on comfort discussing sensitive topics such as sexual behavior. An index of comfort in discussing sexual behavior was constructed out of six items. A question asked the respondents how comfortable they were discussing the following items: (1) HIV/AIDS; (2) sexually transmitted diseases; (3) marriage problems; (4) condom use; (5) going to sex workers; and, (6) use of drugs. When recoded, responses to each item were located on a scale from 1 (not comfortable), 2 (somewhat comfortable), 3 (comfortable), to 4 (very comfortable). The index was constructed by summing responses to the six items and then dividing by 6 to obtain final index values that varied from 1 to 4 , reflecting the underlying measurement scale of each item.

\section{Data analysis}

The analysis of the impact of the two interventions primarily utilizes data from the first and second round of surveys, and compare changes between baseline and six months. While there is also a third round of data collection at one year, the $\mathrm{HC}$ sites are entirely new, and the comparison 
between the existing PE sites and the new HC sites at year one is not appropriate. The full year of data was utilized for the costing analysis and for comparisons within arms. Data from the questionnaires were coded by the interviewers and input into the computer using a double entry system. Data analysis was undertaken using SPSS.

All in-depth interviews and FGDs were tape recorded and fully transcribed by interviewers or others soon after the field work. The completed transcripts were reviewed by the persons who conducted the IDIs and FGDs. The complete data set was coded and analyzed primarily by one principal investigator according to the key themes decided upon before data collection. Then, preliminary qualitative data analysis findings were discussed among the principal investigators and findings integrated into the analysis.

Throughout the project, detailed information was kept on indirect and direct costs through costing forms filled out by project staff and monitoring forms filled out by PEs and HCs. In each approach, both start-up (e.g., training) and operating costs (e.g., staff time, meeting expenses, cost of condoms) were estimated. 


\section{Results}

\section{Workers}

\section{Characteristics of workers}

Survey findings show that the great majority of workers were male ( $\sim 85$ percent) and in their late 20s. Most had completed "lower secondary" school or less. About half were married. Most had lived in HCMC for less than two years. However, workers in HC sites, compared to PE sites, were significantly more likely to be male, have higher levels of education, be single and younger and have lived in Ho Chi Minh City for a shorter period of time (see Table 1).

Table 1 Sociodemographic characteristics of workers, by survey round and intervention arm

\begin{tabular}{|c|c|c|c|c|c|c|c|c|c|}
\hline \multirow[t]{2}{*}{ Characteristic } & \multicolumn{2}{|c|}{ Round 1} & & \multicolumn{2}{|c|}{ Round 2} & \multicolumn{4}{|c|}{ Round 3} \\
\hline & $\begin{array}{c}\text { PE } \\
n=742\end{array}$ & $\begin{array}{c}\text { HC } \\
n=502\end{array}$ & & $\begin{array}{c}\text { PE } \\
\mathrm{n}=751\end{array}$ & $\begin{array}{c}\text { HC } \\
n=505\end{array}$ & & $\begin{array}{c}\text { PE } \\
n=363\end{array}$ & $\begin{array}{c}\text { HC } \\
n=211\end{array}$ & \\
\hline Sex (\%) & & & ** & & & ** & & & ** \\
\hline Male & 81 & 90 & & 76 & 84 & & 80 & 90 & \\
\hline Female & 19 & 10 & & 24 & 16 & & 20 & 10 & \\
\hline Education (\%) & & & ** & & & $* *$ & & & ** \\
\hline Primary or less & 39 & 22 & & 34 & 24 & & 30 & 22 & \\
\hline Lower secondary & 44 & 47 & & 47 & 44 & & 49 & 44 & \\
\hline $\begin{array}{l}\text { Higher secondary } \\
\text { or greater }\end{array}$ & 17 & 32 & & 19 & 32 & & 21 & 35 & \\
\hline Marital status (\%) & & & ** & & & ** & & & ** \\
\hline Currently married & 52 & 40 & & 48 & 40 & & 55 & 43 & \\
\hline Never married & 45 & 58 & & 49 & 58 & & 42 & 55 & \\
\hline Formerly married & 3 & 2 & & 3 & 2 & & 4 & 2 & \\
\hline $\begin{array}{l}\text { Duration in Ho Chi } \\
\text { Minh City (\%) }\end{array}$ & & & * & & & $* *$ & & & \\
\hline$<6$ months. & 28 & 32 & & 21 & 40 & & 21 & 25 & \\
\hline $6-24$ months & 20 & 24 & & 32 & 30 & & 30 & 24 & \\
\hline 25 - 60 months & 19 & 17 & & 14 & 14 & & 15 & 16 & \\
\hline $61+$ months & 34 & 27 & & 32 & 17 & & 35 & 30 & \\
\hline $\begin{array}{l}\text { Mean age in years } \\
(+/-S D)\end{array}$ & $\begin{array}{l}29.0 \\
(10.2)\end{array}$ & $\begin{array}{l}28.1 \\
(9.8)\end{array}$ & & $\begin{array}{l}29.4 \\
(10.1)\end{array}$ & $\begin{array}{c}28.4 \\
(9.0)\end{array}$ & & $\begin{array}{l}30.6 \\
(10.0)\end{array}$ & $\begin{array}{l}27.7 \\
(9.7)\end{array}$ & ** \\
\hline
\end{tabular}




\section{Exposure to program activities}

Among workers surveyed, a higher proportion of workers at PE sites had contact with the intervention than did workers at the $\mathrm{HC}$ sites and were exposed for longer periods of time. At six months follow-up, 73 percent of workers at peer education sites had direct experience with program activities, such as group or one-on-one sessions, with 4.6 the mean number of months of exposure. In contrast, 57 percent of the workers at the health communicator sites were exposed to the health communicators, with the mean length of exposure only 3.7 months. Levels of exposure during the second six months of the intervention declined to 61 percent for the workers at the PE sites and 45 percent for workers at the HC sites.

The reduction in exposure to peer education between rounds two and three likely reflects the dilution of the intervention as workers went to new sites. Since most of the peer educators confined their peer education activities to their work teams, other work teams on new sites might not have had access to peer educators. This points to the importance of continuing to train new peer educators at new sites.

Monitoring data collected weekly by peer educators and health communicators about the intensity of program activities are consistent with these findings and show that overall, PEs contacted more workers through small group sessions than through individual sessions, with an average of three persons per week contacted through group sessions, compared to between one and two through individual sessions. The average time spent each week by PEs on peer education activities was 46 minutes. HCs spent an average of 31 minutes at each site and contacted an average of 1.8 persons per site per week.

The PE intervention appeared to be more successful at distributing condoms to workers than the $\mathrm{HC}$ intervention. At six months, 88 percent of workers at PE sites who had contact with PEs reported that they had received condoms, compared to 76 percent of workers who had contact with HCs $(\mathrm{p}<.01)$. At 12 months, 78 percent of workers at PE sites and 65 percent of workers at HC sites reported the same $(\mathrm{p}<.01)$. Both the $\mathrm{HC}$ and the PE interventions were successful in ensuring that contacted workers were encouraged to ask HIV-related questions and were provided with relevant IEC materials. At both six months and at the end of one year, approximately 90 percent of contacted workers at both $\mathrm{HC}$ and PE sites had received IEC materials, and more than 80 percent of contacted workers had asked HIV-related questions of either HCs or PEs.

Qualitative data also confirm that the peer education intervention activities successfully led to the distribution of condoms. As peer educators stated in a focus group:

When I distributed condoms to workers, some people did ask me, "What is it?" But now they all know the use of condoms.

Some people did not know how to use a condom, and others used them incorrectly. I showed them how to use a condom correctly. 


\section{Hgrizons}

\section{Improvements in HIV-related knowledge, norms, skills, and stigma reduction}

At baseline, the level of HIV/STI knowledge for workers was high, with a mean of more than six of eight items correct for workers in both intervention sites. At six months, the mean knowledge score increased to 7.3 for workers at both the peer education and the health communicator sites ( $p$ $<.01)$. Knowledge also increased for workers at the PE sites who did not have direct exposure to activities with peer educators (i.e., non-exposed), but this increase was not found among workers at the HC sites who were not directly exposed to health communicators. Table 2 (see page 21) highlights the statistical comparison between the HC and PE sites and between workers exposed and not exposed to activities, as well as the net effect of the interventions.

Qualitative data support the finding that knowledge increased. As one peer coordinator stated:

Many workers told me that they understood how dangerous AIDS is and how to prevent it through this program. These things they never knew before. Not until the program was implemented did many people know how to use a condom.

As health communicators stated during a focus group:

When I first went to the site to talk about AIDS with workers, some people told me, "I don't care about AIDS. Why do you talk to me?" But next time, they came to ask me questions about HIVIAIDS.

When I did not answer questions asked by someone in a group of workers, other [construction workers] answered them instead of me. I found the answers correct. I think that their knowledge increased.

There were also large increases in the proportion of workers who stated that they had heard of sexually transmitted infections (STIs). At baseline, the percent reporting knowledge of STIs was in the mid-60s for both arms. This rose to 92 percent $(\mathrm{PE})(\mathrm{p}<.01)$ and 88 percent $(\mathrm{HC})(\mathrm{p}<.01)$ for those exposed to the interventions, and to $82(\mathrm{p}<.01)$ and 75 percent for those workers not exposed to the interventions.

As one worker stated:

STDs include syphilis, gonorrhea, chancroid, etc. If I got these diseases I would go to the City Venerology and Dermatology Hospital. Mr. C. [peer educator] distributed to me a piece of paper with the address of this hospital. I put it in my wallet. Sometimes I would go there to have check-ups...If I got these diseases I would say to him, "Mr. C, I have a problem... Could you tell me how to treat it and where I should go?" I believe he could help me. (Male worker, 46, married, PE site)

At baseline, 63 percent of workers at PE sites and 68 percent of workers at $\mathrm{HC}$ sites knew where to obtain a condom. At six months, a greater proportion of workers directly exposed to PE activities (94 percent) as well as non-exposed workers at the PE sites (75 percent) knew where to obtain a 
condom $(\mathrm{p}<.01)$. At HC sites, only 75 percent of workers knew where to obtain a condom six months after the intervention began, and for non-exposed workers, this number decreased from baseline (66 percent).

Apart from attempting to increase knowledge, the health communicator and peer education interventions also attempted to promote norms in support of HIV risk reduction, such as the acceptability of carrying condoms on one's person. The mean score on the sexual norms index increased for both exposed and non-exposed workers at the peer education sites $(p<.01)$ and nonexposed workers at the health communicator sites $(\mathrm{p}<.01)$. The mean values can be interpreted as the number of items where sexual norms are supportive of preventive behaviors. The increase was greatest for workers exposed to the peer education interventions.

The interventions also attempted to increase the confidence of workers to make decisions in everyday situations they might face that would reduce their vulnerability to HIV/AIDS. Fostering these decision-making skills, or life skills, is believed to be an important step in promoting behavior change. Life skills were measured by providing respondents with seven hypothetical situations and asking them to express, on a scale of 1 to 10 , how confident they would be in each situation in making a specified decision. For both groups of workers, the mean score on the life skills index at baseline was approximately 7.3. Among workers exposed to the peer education interventions, the mean score increased to 7.8 after six months $(\mathrm{p}<.01)$, while there was a smaller increase to 7.6 for the workers exposed to the health communicator interventions $(p<.01)$, and almost no change for workers not exposed to the interventions.

In addition to life skills in general, an additive index was constructed to measure the extent to which workers felt confident in specifically using a condom. The index was constructed from two items, each of which was scored one to four, with increasing values reflecting greater comfort/confidence related to condom use. For workers exposed to the interventions, the mean condom efficacy score increased from 2.89 to 3.02 at the peer education sites and from 2.95 to 3.19 at the health communicator sites $(\mathrm{p}<.01)$. There was very little change for workers not exposed to the intervention. The results suggest that direct exposure to the interventions was necessary to bring about a change in the confidence of workers to obtain and use condoms, but that both the peer education and health communicator interventions were effective in bringing about change.

Qualitative data also suggest that the peer education intervention activities influenced workers' self-efficacy to use condoms. As one peer coordinator observed:

When I...visit a site, I was impressed that even young female construction workers seemed not to be embarrassed to display how to use a condom. (Director, Social Work Center, HCMC Labor Union)

An important feature of many prevention programs is to encourage people to reflect on their risk of contracting HIV and to realistically assess that risk. At the start of the interventions, very few workers thought that they had any risk of contracting HIV. At baseline, 9 percent of workers at the peer education sites and 8 percent of workers at the health communicator sites stated they felt they had a risk of contracting HIV. Six months later this had increased to 21 percent of the workers 


\section{Hgrizons}

exposed to intervention activities at the peer education sites and 30 percent of those at the health communicator sites $(\mathrm{p}<.01)$. There were also significant although smaller increases among the workers not exposed to the interventions at the two sites.

Components of both the health communicator and peer education programs attempted to reduce stigmatizing attitudes toward persons living with HIV/AIDS. The survey results suggest that the interventions did have an impact on reducing stigma, with the reductions greatest for those workers in the peer education sites, and the impact largely confined to workers directly exposed to intervention activities. An index of stigmatizing attitudes was constructed from five items. For workers exposed to intervention activities at the peer education sites, there was a reduction on the index from 0.47 to $0.32(\mathrm{p}<.01)$, while for workers exposed to intervention activities at the health communicator sites, the index fell from 0.38 at baseline to 0.28 six months later $(\mathrm{p}<.01)$.

\section{PE sites reported greater positive changes on key impact variables than workers at HC sites.}

As shown in Table 2, there were statistically significant improvements in selected impact variables among workers at peer education sites between baseline and six months after the program was initiated. Even for workers at the PE sites who were not directly exposed to PE activities, there were significant increases in most of the variables. For workers exposed to the HC program, changes between baseline and six months later were also statistically significant, with the exception of the sexual norms index. For non-exposed workers at $\mathrm{HC}$ sites, no change was generally seen.

However, after controlling for differences in the sociodemographic composition of workers, positive changes at the PE sites were significantly greater in a number of variables than at the $\mathrm{HC}$ sites (i.e., net effect). Workers at the PE sites who had contact with the intervention were significantly more likely to know where to get a condom after being exposed to the interventions than were workers who had contact with the HC interventions. This may partially be a result of onsite availability of condoms at the peer education sites, but the peer educators also personally distributed more condoms than the health communicators, and the health communicators had condoms left over at the end of the intervention period. The increase in the mean score on the sexual norms index was significantly greater for workers exposed to the PE interventions compared to workers exposed to the $\mathrm{HC}$ interventions. An unexpected result was the statistically greater increase in knowledge of HIV/STIs among workers not directly exposed to the intervention at the $\mathrm{PE}$ sites than workers not directly exposed to the intervention at the HC sites. This is likely a result of increased communication about HIV/AIDS between exposed and unexposed workers at the PE sites. 
Table 2 Parameter estimates of change between round 1 and round 2 surveys for selected psychosocial variables, by study arm and intervention exposure

\begin{tabular}{|c|c|c|c|c|c|c|}
\hline \multirow[t]{2}{*}{ Variable } & \multicolumn{2}{|c|}{ Peer Educator Arm } & \multicolumn{2}{|c|}{$\begin{array}{c}\text { Health } \\
\text { Communicator Arm }\end{array}$} & \multicolumn{2}{|c|}{ Net Effect $^{c}$} \\
\hline & $\begin{array}{c}\text { No } \\
\text { Exposure }\end{array}$ & Exposure & $\begin{array}{c}\text { No } \\
\text { Exposure }\end{array}$ & Exposure & $\begin{array}{c}\text { No } \\
\text { Exposure }\end{array}$ & Exposure \\
\hline $\begin{array}{l}\text { Knowledge of } \\
\text { HIVIAIDS }^{\text {a }}\end{array}$ & $0.96^{\star *}$ & $1.28^{* *}$ & 0.03 & $1.17^{* *}$ & Positive* $^{*}$ & None \\
\hline $\begin{array}{l}\text { Know where to get } \\
\text { condom }{ }^{b}\end{array}$ & $1.77^{* *}$ & $8.96^{* *}$ & 0.90 & $3.25^{\star *}$ & None & Positive** \\
\hline Heard of STIs ${ }^{b}$ & $2.33^{\star *}$ & $5.82^{* *}$ & 1.41 & $3.75^{\star *}$ & None & None \\
\hline Condom efficacy ${ }^{a}$ & -0.11 & $0.14^{* *}$ & -0.06 & $0.25^{\star *}$ & None & None \\
\hline Sexual norms $^{a}$ & $0.57^{\star *}$ & $0.92^{* *}$ & $0.45^{\star *}$ & 0.20 & None & Positive** \\
\hline Life skills $^{a}$ & 0.21 & $0.53^{* *}$ & 0.04 & $0.36^{\star *}$ & None & None \\
\hline Perception of risk ${ }^{b}$ & $2.46^{* *}$ & $2.89^{* *}$ & $2.24^{* *}$ & $5.06^{* *}$ & None & None \\
\hline HIV-related stigma $^{a}$ & $-0.07^{* *}$ & $-0.15^{\star *}$ & 0.03 & $-0.10^{* *}$ & None & Positive* \\
\hline \multicolumn{7}{|c|}{$\begin{array}{l}{ }^{*} p<.05 ;{ }^{* *} p<.01 \\
\text { a Parameter estimates are from ANOVA and measure the amount of change in the value of the dependent } \\
\text { variable between round } 1 \text { and round } 2 \text {. } \\
\text { b Parameter estimates are from logistic regression and are odd ratios that measure the ratio of the odds of the } \\
\text { event occurring in round } 2 \text { compared to round } 1 \text {. } \\
{ }^{\circ} \text { The net effect is estimated from an interaction between round and intervention arm. If the interaction is } \\
\text { positive, it means that the amount of change in the outcome variable between round } 1 \text { and round } 2 \text { was } \\
\text { significantly greater in the peer education arm than in the health communicator arm. If the net effect is } \\
\text { negative, the amount of change was greater in the health communicator arm. None means that amount of } \\
\text { change in the outcome variable is not significantly different between the two arms. The models that estimated } \\
\text { the net effect also controlled for age, sex, education, duration of residence in Ho Chi Minh City, and marital } \\
\text { status. }\end{array}$} \\
\hline
\end{tabular}

\section{There is some evidence of increased condom use, although workers report low levels of sexual risk behavior.}

Reported levels of sexual and other behaviors over the previous six months that could expose workers to HIV risk were low in the close-ended surveys. In Table 3, the reported levels of various behaviors are shown at baseline and six months after the intervention began. The results at six months are divided between those exposed to the intervention and those not exposed to the intervention.

Averaged over the three rounds, only about half of workers reported sexual activity and the great majority occurred with a spouse. The high levels of sexual activity with a spouse suggest that many married construction workers either come to Ho Chi Minh City with their wives or make regular trips home. On average, less than 1 percent reported having experienced an STI in the six months prior to the baseline survey. Less than one-half of 1 percent reported ever having injected drugs. Approximately 20 percent of workers reported that they had been drunk at least once over the last 


\section{Hgrizons}

month. Reported sex with sex workers and non-marital partners increased in both groups, which may represent greater willingness of respondents to accurately report sexual behavior in round 2 .

Table 3 Selected behavior variables, by study arm, survey round, and exposure to intervention

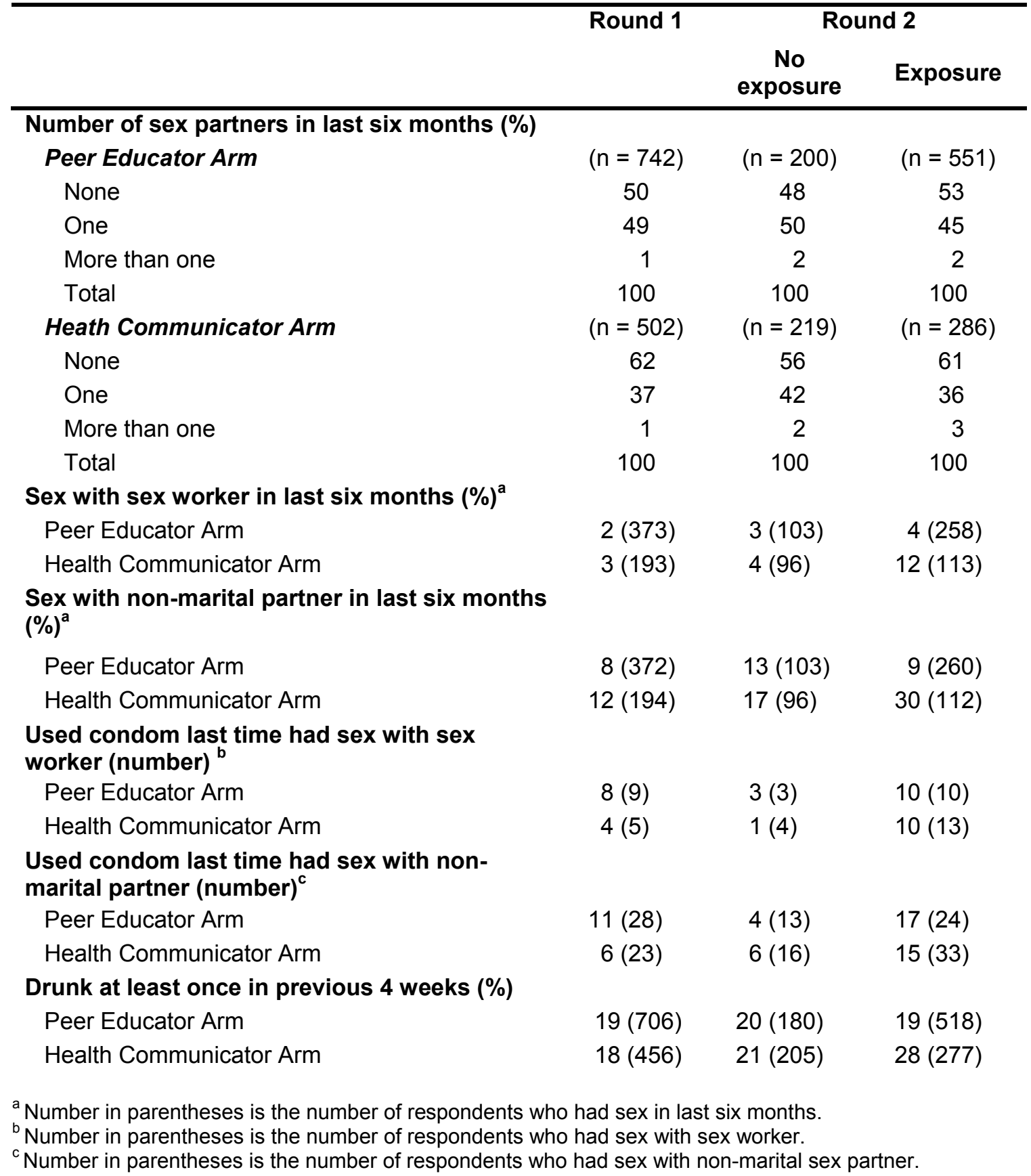


The qualitative data suggest that there was underreporting of sexual risk behaviors, including nonmarital sexual behavior and substance use. This highlights the importance of triangulating the information gathered from multiple sources. As the peer educators stated in a focus group discussion in response to the moderator's question, "Do you think construction workers are at risk of HIV infection?"

Yes. Most construction workers drink alcohol. When becoming drunk, they can lose control of their behaviors. For example, when having sex with sex workers, they may forget to use a condom.

The majority of workers here came from other rural provinces. Because of living far away from home, they often go drinking in the evening, especially on the weekends, and then they seek entertainment services [go to brothels].

And the health communicators agreed:

Most construction workers are young and live far away from home.

They are free from their family.

Every Saturday they invite each other to a cafe or to drink, and then think about sex. Some people are still single and others are married, but all have sexual desire.

They often drink on the weekend, and then visit sex workers.

Workers in many of the in-depth interviews also talked about sexual relations without condoms with sex workers as well as other sexual partners:

I have a medium risk [of HIV] because I sometimes have sex with my girlfriend, and once in a while I visit sex workers. One time having sex with a sex worker, I did not use condoms. I was very nervous so I did take an HIV test. Luckily, the test was negative. I was relieved. (Male worker, 33, divorced, PE site)

\section{Qualitative data and some quantitative evidence indicate risk reduction at follow-up.}

Workers reported relatively high use of condoms with sex workers and casual partners in the closeended surveys, although some indication of increases in condom use can be found by six months into the intervention (see Table 3). Condom use at last sex was reported by about a third of workers $(\mathrm{n}=17 / 51)$ with non-marital partners at baseline; this proportion increased substantially at six months among workers exposed to the PE program (71 percent) and less so for workers exposed to the HC program (45 percent). Condom use with sex workers was relatively high at both baseline and follow-up, with 86 percent $(n=12 / 14)$ of workers who had sex with a sex worker reporting condom use during last sex at baseline, and 80 percent among workers exposed to the PE program and 77 percent among workers exposed to the $\mathrm{HC}$ program at six months follow-up. 


\section{Hgrizons}

The in-depth interviews with workers suggest that they were engaging in behaviors that could increase their vulnerability to HIV but that they also sought advice from peer educators about these behaviors. As one worker stated:

I asked him [peer educator], "A woman I have known has been 'friendly' with three or four men. Am I at risk of HIV, if I have sex with her?' He said, 'To be safe, you should use a condom.' I found his answer reasonable." (Male worker, 33, married, PE site)

As another worker stated:

I went out [had sex] with a girl, and then I got an illness. I asked him [peer educator], 'Do you know where I can go for treatment?' He did tell me where. (Male worker, 30, unmarried, PE site)

Qualitative findings also indicate that the intervention had a substantial effect on the HIV risk behavior of workers exposed to the peer education program. As a peer educator stated during a focus group:

Construction workers living far away from home used to drink a lot on the weekend, and then went to the karaoke bar to have 'the second shift' or 'the third shift' [visited sex workers], but never used a condom. After listening to us [peer educators], they carried condoms whenever they went to these places.

A worker from a peer education site stated:

Mr. C. [peer educator] regularly distributed condoms to us and reminded us to ask him for condoms. As a man he understood our sexual desire. Therefore I am not embarrassed to ask him. (Male worker, 46, married, PE site)

Peer educators also stated that their experiences have had an effect on their own risk behaviors:

In the past when I did not know anything, not only other workers but also myself went out [visited sex workers] very often. But during the year since I have attended the training, I go to work in the morning and come back home in the afternoon right away. I no longer go to drink and visit sex workers after working hours as before. I myself have changed such behaviors.

It was difficult for health communicators to observe behavior changes among construction workers, as they did not spend a great deal of time on site with workers. As a health communicator stated:

There is certainly awareness of HIVIAIDS now, but it is difficult to know whether they [construction workers] changed their behaviors or not.

In summary, both the peer education and health communicator interventions were associated with statistically significant changes in a variety of knowledge-, attitude-, and skills-related variables. 
However, the changes were typically greater for workers at the PE sites than for workers at the HC sites. Furthermore, for many variables the changes for workers at the peer education sites occurred both for those exposed to the interventions and those not exposed to the interventions. However, for workers at the health communicator sites, the changes were mainly confined to those exposed to the interventions. It appears that there are considerable diffusion effects associated with the peer education intervention. Although low levels of reported risk behaviors in the surveys, as opposed to the qualitative interviews, made it difficult to establish significant levels of change in these variables, both the quantitative and qualitative data suggest that the interventions were able to reduce risk behavior, with the peer education intervention most successful in this regard.

\section{Peer Educators and Health Communicators}

This operations research study compared two workplace HIV prevention programs for highly mobile construction workers: the existing health communicator program and a new peer education program. At the outset, the health communicator program had a number of positive characteristics, including minimal costs for implementing the program and a large supply of motivated and knowledgeable educators. However, local authorities expressed concerns about the substantial turnover of health communicators and whether social work students, about half of whom are female, would be the most effective HIV prevention educators for a largely male construction worker population.

The new program uses construction worker peer educators to promote HIV risk reduction and fosters management involvement and support for the workplace program. While peer education programs have been found to be effective in many settings because they are perceived to be more credible than outsiders, local authorities were concerned about whether construction workers could be capable educators and could be motivated to stick with the program. The section below highlights the backgrounds, capabilities, and retention of the health communicator and peer educators, as well as the ability of peer educators to continue their activities at new sites.

\section{Characteristics}

There are some noticeable differences between the characteristics of peer educators and health communicators. About half of the HCs were male, while the great majority of PEs were male. While a small proportion of construction workers were female ( $\sim 15$ percent), and female PEs and HCs tended to work with other females, there were also a number of female HCs who interacted regularly with male workers. In addition, HCs were more likely than PEs to be younger, single, have higher levels of education, and have lived in Ho Chi Minh City for a shorter period of time (see Table 4). PEs tended to be more educated and have lived in Ho Chi Minh City longer than their fellow workers. These differences were expected, since PEs were primarily drawn from the ranks of workers and health communicators were primarily students completing their social work degrees, but these differences also potentially influenced the effectiveness of the different educator groups. 
Table 4 Sociodemographic characteristics of peer educators and health communicators, by survey round

\begin{tabular}{|c|c|c|c|c|c|c|c|c|c|}
\hline \multirow[t]{2}{*}{ Characteristic } & \multicolumn{2}{|c|}{ Round 1} & & \multicolumn{2}{|c|}{ Round 2} & \multicolumn{4}{|c|}{ Round 3} \\
\hline & $\begin{array}{c}\text { PE } \\
n=68\end{array}$ & $\begin{array}{c}\text { HC } \\
n=69\end{array}$ & & $\begin{array}{c}\mathrm{PE} \\
\mathrm{n}=56\end{array}$ & $\begin{array}{c}\mathrm{HC} \\
\mathrm{n}=46\end{array}$ & & $\begin{array}{c}\mathrm{PE} \\
\mathrm{n}=45\end{array}$ & $\begin{array}{c}\text { HC } \\
n=45\end{array}$ & \\
\hline$\overline{\operatorname{Sex}(\%)}$ & & & ** & & & $\overline{k *}$ & & & ** \\
\hline Male & 87 & 36 & & 91 & 50 & & 87 & 40 & \\
\hline Female & 13 & 64 & & 9 & 50 & & 13 & 60 & \\
\hline Education (\%) & & & ** & & & ** & & & ** \\
\hline Primary or less & 19 & 0 & & 20 & 0 & & 16 & 0 & \\
\hline Lower secondary & 38 & 0 & & 34 & 0 & & 40 & 0 & \\
\hline $\begin{array}{l}\text { Higher secondary } \\
\text { or more }\end{array}$ & 43 & 100 & & 46 & 100 & & 44 & 100 & \\
\hline Marital status (\%) & & & $* *$ & & & ** & & & ** \\
\hline Currently married & 52 & 0 & & 66 & 0 & & 65 & 2 & \\
\hline Never married & 48 & 100 & & 32 & 100 & & 29 & 98 & \\
\hline Formerly married & 0 & 0 & & 2 & 0 & & 7 & 0 & \\
\hline $\begin{array}{l}\text { Duration in Ho Chi } \\
\text { Minh City (\%) }\end{array}$ & & & ** & & & * & & & \\
\hline $\begin{array}{l}\text { Less than } 6 \\
\text { months }\end{array}$ & 15 & 0 & & 7 & 2 & & 0 & 0 & \\
\hline 6-36 months & 18 & 52 & & 27 & 44 & & 27 & 40 & \\
\hline $37-120$ months & 21 & 28 & & 52 & 28 & & 60 & 38 & \\
\hline 121+ months & 47 & 20 & & 14 & 26 & & 13 & 22 & \\
\hline $\begin{array}{l}\text { Mean age in years } \\
(+/-S D)\end{array}$ & $\begin{array}{l}30.6 \\
(10.2)\end{array}$ & $\begin{array}{l}20.8 \\
(2.3)\end{array}$ & $* *$ & $\begin{array}{l}34.7 \\
(9.8)\end{array}$ & $\begin{array}{c}21.5 \\
(2.0)\end{array}$ & ** & $\begin{array}{l}33.1 \\
(10.2)\end{array}$ & $\begin{array}{l}21.2 \\
(2.1)\end{array}$ & ** \\
\hline
\end{tabular}

\section{Retention rates}

An ongoing concern had been the high level of dropouts from the $\mathrm{HC}$ programs and the need to keep recruiting and training new HCs. However, there was also a concern that many PEs would be lost when they moved to new work sites. The results from this study indicate that there was significant turnover with both groups, although the turnover was greater among HCs than PEs (see Figure 1). Approximately two-thirds of the PEs who started the program remained after six months, compared to 55 percent of the HCs. At 12 months, 52 percent of the PEs remained, compared to 43 percent of the HCs. 
Figure 1 Percent of original cohort remaining in project

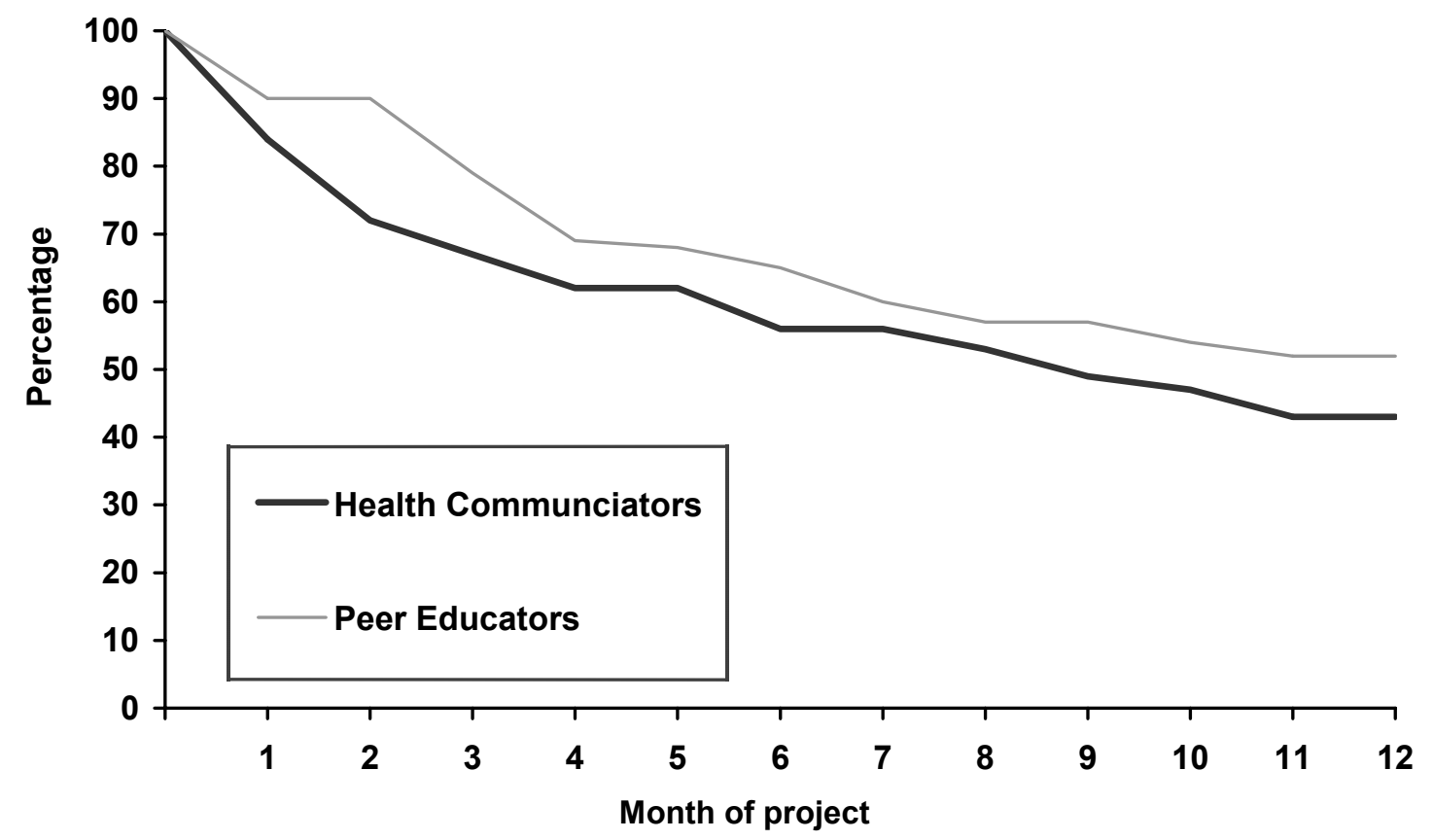

The first month of the project was the critical period for dropping out. By the end of the first month, only 90 percent of peer educators and 84 percent of health communicators remained in the program. In fact, several of those trained as peer educators never commenced activities. For some of the peer educators, this was because they were too busy to participate. A large number of health communicators went home for their summer student holidays and did not return. The main reason for losing peer educators was that they went home or to other construction sites outside of Ho Chi Minh City where they could not be followed up. For the health communicators, exams, graduation, and shifting to other volunteer programs were the main reasons for dropping out.

Qualitative data provide further insight into some of the differences between why PEs and HCs dropped out of the program. The reasons peer educators gave for dropping out of the program included lack of support from their fellow workers, weak communication and facilitation skills, and shifts in their workplaces that caused them to move great distances away. In contrast, health communicators discontinued their participation in the program because of a lack of spare time, scheduling conflicts, a lack of transportation, a lack of interest in the program, and obtaining other employment. A few female health communicators also described embarrassing exchanges with male construction workers when discussing the sensitive issues addressed in the program, which implies possible harassment by male construction workers and raises the need to be sensitive to the appropriate match between educators and their audience. As health communicators stated in a focus group discussion: 


\section{Hgrizons}

Some people dropped out due to being busy studying, conflicts in their schedules, or the need to travel to far-away sites.

Others were not really interested in this activity. They joined the program because of their friends. Therefore, they felt it was boring to distribute condoms and leaflets to workers.

Some people got a job after graduation.

Some male construction workers teased female health communicators. For example, they asked these HCs to display how to use a condom. These people felt very embarrassed and consequently quit this work.

As peer educators stated in a focus group discussion:

Some peer educators here did not participate in the program any more due to their own difficulties. For example, they had to move very often to different work sites so they could not keep working for the program, or they went abroad.

Other peer educators were frustrated when workers did not listen to them or had ideas in conflict with theirs.

\section{Peer educators' ability to follow a mobile workforce and continue HIV/AIDS activities}

One important objective of the study was to explore whether a peer education program can successfully move with a highly mobile work force and whether peer educators can continue education activities with their fellow workers in different work sites over time. An underlying premise of the peer education program was that the mobility of peer educators could be used to spread the peer education models among construction sites and companies. This would increase the number of workers reached, increase the retention of peer educators, and help in the recruitment of new companies. Within the limitations of the budget for both follow-up and the ability to train many new peer educators, the project was successful in meeting its aims.

The number of sites covered by the intervention expanded rapidly as peer educators moved to new sites. By the time the intervention began, the peer educators selected from the six original sites were scattered across 11 sites. The maximum number of sites included in the program at any one time was 19, and at the end of one year 16 sites remained in the program. Overall, peer education activities were conducted at 31 construction sites through the 12 months of the intervention.

The majority of peer educators who moved from the original six construction sites went to work at other sites in Ho Chi Minh managed by the companies participating in the study and the project was able to follow-up all of these peer educators. Only those peer educators who went to work for other companies or who left Ho Chi Minh City could not be followed up. It appears that there is relatively limited mobility of workers at the level of team leaders, who are those most likely to be 
trained as peer educators. However, over the course of the project, some of the peer educators moved to provinces outside of Ho Chi Minh City. Others moved out of construction work into other occupations.

Focus group discussions with peer educators revealed that mobility was a barrier to continued participation in the program. Peer educators generally wished to continue activities even after moving to new sites, but it was difficult do this without the support of the peer coordinators. In discussing how to resolve the difficulty of movement, a peer educator said:

If we move far away, we still want to continue participating in the program. But we need to keep in touch with the peer coordinators, by making phone calls or by driving to meet them. Will the program cover that cost? (PE from Sai Gon Tourism construction site)

\section{HIV/AIDS knowledge of PEs and HCs}

Analysis in the following sections is restricted to PEs and HCs who completed the baseline survey and were followed over time.

Concerns about the PEs included their lack of knowledge about HIV/AIDS, given their limited experience. At baseline, levels of knowledge were higher among HCs than PEs $(p<.05)$. This difference disappeared by the second round of data collection. Equivalent levels of knowledge were also found after one year. 
Table 5 Mean scores on indexes of knowledge, comfort with discussing sensitive topics, and percentage distribution of motivation to participate in program, by survey round and type of agent

\begin{tabular}{|c|c|c|c|c|c|c|c|c|}
\hline & \multicolumn{3}{|c|}{ Round 1} & \multicolumn{2}{|c|}{ Round 2} & \multicolumn{2}{|c|}{ Round 3} & \multirow{2}{*}{$\begin{array}{c}\text { Net } \\
\text { effect }^{b}\end{array}$} \\
\hline & $\begin{array}{c}\text { PE } \\
n=68\end{array}$ & $\begin{array}{c}\mathrm{HC} \\
\mathrm{n}=69\end{array}$ & & $\begin{array}{c}\text { PE } \\
n=45\end{array}$ & $\begin{array}{c}\mathrm{HC} \\
\mathrm{n}=30\end{array}$ & $\begin{array}{c}\text { PE } \\
n=33\end{array}$ & $\begin{array}{c}\mathrm{HC} \\
\mathrm{n}=40^{\mathrm{a}}\end{array}$ & \\
\hline $\begin{array}{l}\text { Knowledge index } \\
\text { (mean) }\end{array}$ & 6.2 & 6.5 & * & 6.9 & 7.0 & 6.9 & 6.9 & None \\
\hline $\begin{array}{l}\text { Comfort with } \\
\text { discussing sensitive } \\
\text { topics (mean) }\end{array}$ & 2.5 & 3.1 & $* *$ & 3.6 & $3.4 *$ & 3.7 & $3.3^{* *}$ & Positive \\
\hline $\begin{array}{l}\text { Reasons for } \\
\text { participation (\%) }\end{array}$ & & & $* *$ & & & & & None \\
\hline Increase knowledge & 24 & 28 & & 49 & 30 & 46 & 60 & \\
\hline Help workers & 9 & 30 & & 31 & 30 & 39 & 27 & \\
\hline Need for activities & 0 & 13 & & 4 & 7 & 6 & 0 & \\
\hline Personal benefit & 3 & 12 & & 4 & 7 & 0 & 3 & \\
\hline Encouraged by project & 62 & 1 & & 0 & 0 & 0 & 5 & \\
\hline Other & 3 & 16 & & 11 & 26 & 9 & 5 & \\
\hline \multicolumn{9}{|l|}{${ }^{*} p<.05 ;{ }^{* *} p<.01$} \\
\hline \multicolumn{9}{|c|}{$\begin{array}{l}\text { The higher number of health communicators in the round } 3 \text { sample compared to the round } 2 \text { sample is a } \\
\text { result of a group of health communicators not working at the time of the round } 2 \text { survey but returning to work } \\
\text { soon afterward. } \\
\text { bThe net effect is estimated from an interaction between round and intervention arm. If the interaction is } \\
\text { positive, it means that the amount of change in the outcome variable over the three rounds was significantly } \\
\text { greater in the peer education arm than in the health communicator arm. If the net effect is negative, the } \\
\text { amount of change was greater in the health communicator arm. None means that the amount of change in the } \\
\text { outcome variable is not significantly different between the two arms. ANOVA was used for the interval level } \\
\text { variable. For the categorical variable, multinomial logistic regression was used to evaluate the interaction. }\end{array}$} \\
\hline
\end{tabular}

\section{Comfort levels in discussing sexual topics}

An index of comfort in discussing sexual behavior was constructed out of six items. At baseline, HCs were significantly more comfortable discussing topics related to sexual behavior than were PEs $(\mathrm{p}<.01)$. After six months, PEs who remained in the program were more comfortable discussing sensitive topics with workers than were HCs (see Table 5). This gap widened further after one year. 


\section{Reasons for joining the program}

Peer educators reported that their initial motivation for participating in the project was the encouragement of their companies. Almost two-thirds of peer educators stated at round one that their main reason for participation was because company management asked them to. In contrast, the main reasons cited by health communicators for their participation were to increase their own knowledge and to help workers. At six months follow-up, there were no significant differences between health communicators and peer educators in the reasons they gave for participating in the program. For both groups, increasing their own knowledge and helping workers were the two main factors for participation. A similar pattern was evident in round three.

Qualitative data suggest that peer educators and health communicators joined for different reasons as well. As the health communicators stated during a focus group discussion:

The reason I joined the program was to increase my knowledge of HIV/AIDS so that I could help myself first, and then help other people, such as construction workers.

My future profession [social work] requires me to socialize with different people. Meeting and talking with construction workers would help me improve communication skills as well as social work skills.

And as the peer educators stated during a focus group discussion:

We initially became peer educators because of an invitation by the labor union, a decision of the company, and the agreement of site management.

At the beginning we were assigned to attend the training. After the training we enjoyed [the program]. If there is another training, we will voluntarily participate in it. After working in the program, we found we could help ourselves, our family, and society.

Peer educators and heath communicators were drawn from very different populations, had significantly different personal characteristics, and had different motivations for joining the project. Although both the characteristics and motivations of health communicators suggested that they would be more dedicated to their duties and would be more likely to stay in the project, the results indicate that at the end of six months the motivations for participation of peer educators were similar to those for health communicators, that training had provided peer educators with similar levels of skills to health communicators in performing their tasks, and that peer educators were more likely than health communicators to stay in the project.

\section{Management Motivation}

An additional objective of the study was to examine strategies to motivate management to support HIV/AIDS workplace programs in relatively low-prevalence environments. The management motivation component of the intervention took place in the peer education arm, since management 


\section{Hgrizons}

support was needed to implement such a workplace intervention. Management motivation activities did not take place in the health communicator arm, because this intervention arm was to be implemented exactly as it had been previously, and it did not previously include a management motivation component.

Based on interviews with company management and labor union staff, this section highlights findings about how managers can be motivated to support and participate in a workplace HIV/AIDS program, as well as opinions of HIV/AIDS programs from the management perspective. The analysis is largely based on data from in-depth interviews with 12 managers from the companies that participated in the peer education program, six based at construction sites and six based at the headquarters of the companies, and supplemented with interviews from labor union staff. Because the companies who refused to participate were not interviewed, the findings below may not be representative of the views of all managers.

Data from these interviews reveal a number of factors that are associated with motivating construction managers to endorse participation in an HIV/AIDS program:

\section{When managers are aware that their workers are at risk for HIV/AIDS.}

Almost all managers acknowledged that construction workers are vulnerable to HIV infection. They are aware that this vulnerability is enhanced by characteristics specific to this migrant labor force, including spending considerable time away from spouses and home communities, as well as high rates of alcohol abuse and unprotected sex with sex workers.

Construction workers are definitely at risk of HIV infection. ...Living far from home, being young men and living at construction sites, construction workers easily engage in "eating cakes and paying money" [visiting sex workers]. I am not afraid that they use drugs since they do not have much money. I only worry that they are involved in drinking and visiting sex workers. (Vice Director, State Company)

\section{When managers perceive that the wellbeing of workers helps determine the success or failure of the company.}

Most managers perceive the wellbeing of workers as essential to a company's future. They also believe that the company benefits by showing concern for workers, since workers will likely repay such concern with greater efforts to guarantee the success of the company.

I think the health of employees is one of the factors that contributes to the company's success. For example, if 10 percent of workers in a company get sick [not due to AIDS], how much money will be spent on this? (Head of personnel department, state-run company) 


\section{When managers are concerned that uninformed workers may stigmatize or discriminate against fellow workers who are HIV-positive.}

Some managers understood that lack of knowledge about HIV/AIDS could generate negative attitudes among some employees about working with an HIV-positive person, with the resulting fear and conflict leading to declining productivity and teamwork.

When there is one case [of HIV/AIDS] in the company due to any cause, how will other people behave toward this person? People may not want to work with him/her or may request that you transfer him/her to other places. This really affects labor productivity. That is why I think if the goal of the program is to prevent workers from getting AIDS, it is really a good activity to support the company's business. Participating in this program is first to prevent workers from getting AIDS, and second, to change attitudes of our employees toward people living with AIDS. So in case someone is infected with HIV/AIDS in my company, other employees will still treat him/her as a normal person." (Director, state-run company)

\section{When managers are approached by prevention programs in a systematic way that acknowledges the chain of command.}

Busy construction managers appreciated the systematic approach of the labor union in introducing the workplace HIV/AIDS program to the company. This included three steps: (1) sending a formal letter to the director of the company, (2) calling to follow-up and make an appointment with appropriate decision-makers, and (3) providing a formal presentation on the program to company management with decision-making abilities.

In my opinion, a combination of all three ways [letter, telephone and meeting] is the best. If the labor union only sends a letter to me, I think that they are not so enthusiastic because every day I receive so many letters, papers, and faxes. But they were very enthusiastic. They sent me a letter, then called for a meeting. Generally speaking, the company decided to participate in the program not only because of its benefits, but also because of labor union's enthusiasm. This has influenced my decision. They are respectful people. Other institutions send a letter and wait for us to make contact." (Director, state-run company)

The results of the analysis of the decision-making process demonstrate the importance of contacting the company director at the initial stages of the process and providing him or her with an opportunity to consult with others. If the director is not aware of the program, it is unlikely that the company will participate.

As a director, I was the decision maker. ... However, I need to consider opinions of others on the board." (Director, state-run company)

Interviews with program coordinators indicate that the most successful manner in which to motivate management was to work with both top management at headquarters and management at 


\section{Hgrizons}

the construction site itself. Top management should be approached simultaneously with site management, since creating a good relationship with managers at project sites is important to prevent them from feeling pressured to participate in the project.

When we come to a construction site, the site head feels respected; therefore it is very easy for us to have a good relationship with him/her. He/she won't be surprised when his/her company agrees to participate in the project. (Vice-director, Social Work Center)

\section{When managers receive a convincing presentation from a credible source that addresses estimated costs to the company.}

The presentation introducing the program was designed to openly address issues of potential concern to construction managers. This included the amount of time needed to implement the HIV/AIDS program activities and findings about cost-effectiveness of other programs. Because training is needed to support a program built around peer education, management needs to provide time for workers to attend peer education workshops. It is important for programmers to raise these issues in the beginning and be flexible about program modifications that would be more appropriate for specific work environments.

I agreed to participate in the program with the condition that it does not trouble the company too much. I mean that the program should not take too much time or require a large number of people. For example, if all work-team leaders go to the training at the same time, like a "snake without a head" it will affect the productivity of the company. (Director, state-run enterprise)

The presentation played an important role in making the final decision to participate in the workplace HIV/AIDS program.

Attending the presentation session was one of the factors leading me to participate in the program. If I did not attend the presentation session, I would not be so convinced about participating in the program. Nothing is comparable to seeing and hearing." (Head of personnel department, state-run company)

In addition, most of the construction companies have an ongoing and trusting relationship with the labor union, which added to their willingness to set up introductory meetings as well as agree to implement the program.

Time is my major concern. I thought the program would take too much of our time, but after listening to the program presented by the labor union, I realize that it does not take much time and does not affect the company's work." (Director, state-run company) 


\section{When managers believe that their companies have a responsibility to Vietnamese society as a whole.}

Many managers said that the growing numbers of those with HIV/AIDS in Vietnam is a serious issue and that their companies should be involve in reducing the impact of HIV/AIDS as part of their responsibility to Vietnamese society. An interesting point is that most managers did not expect program participation to improve the public image of their company, believing that it depends largely on the quality and price of their services and their ability to adhere to schedules.

Participating in this program is our responsibility. I think that every person should have responsibility for the country to prevent this pandemic. (Director, state-run company)

The research with management indicates that in Vietnam, construction companies can be successfully motivated to participate in, and support, a workplace peer education HIV/AIDS program. The use of an official and widely accepted organization such as the labor union was essential in obtaining the initial hearing of managers, which was so important to getting their support. Equally important was the systematic approach adopted by the labor union, which included a presentation of details of the workplace HIV/AIDS program. While the potential economic impact of HIV/AIDS on companies was a factor in motivating participation by companies, more important for the managers who became involved in the program was their desire to help their workers and Vietnamese society.

\section{Cost Analysis}

Local authorities in Vietnam want to scale up their HIV prevention efforts and require information on the effectiveness and cost of activities, as well as their potential for scaling up. Therefore, a key component of this operations research is a costing analysis. The analysis below compares the costs of the health communicator program with the new peer education program.

The cost analysis is presented in two ways: a productivity analysis that compares the cost of reaching a construction worker through each approach, and an analysis of the costs of replicating the intervention. First, to give some background on how the intervention was financed, several agencies and institutions provided funding for the two interventions. The Ford Foundation paid for much of the costs of training and implementing the peer education intervention, while the Horizons Program paid for much of the costs of training and implementing the health communication intervention. Other international donors had previously paid to train some of the health communicators that were involved in the current intervention. The local Vietnamese institutions (government-financed) provided the commodities (condoms and brochures) and some of the time of their personnel in developing and implementing the interventions. Construction companies contributed some of the time of their construction workers for training as peer educators. 


\section{Hgrizons}

\section{Start-up and service delivery costs}

The costs of the peer education and health communication programs are divided into two types: start-up and service delivery. Start-up costs included training for health communicators, peer educators, and program coordinators. Another start-up cost, the cost of designing the interventions, is not included because no information on this was available for the health communicator intervention. It should be noted that excluding design costs might result in an underestimation of some of the costs of the peer educator intervention. Training costs included the value of the time of trainers and trainees as well as costs of materials, venue fees, and stationery for the intervention. The value of the trainee time was based on the daily allowances given to them during the trainings, that is, daily wage rates were paid to the peer educators and an allowance of 25,000 dong was paid to the health communicators. The local exchange rate was approximately 15,000 dong per dollar.

The costs of delivering the intervention included labor costs: i.e. the time of health communicators and peer educators, program coordinators, and other labor union and HCMC AIDS Committee staff, cost of condoms and brochures, stationery, transport, and miscellaneous expenses (e.g., meeting costs). The value of the time of the PEs and HCs was assumed to be the stipend/allowances that both received. Because PEs and HCs almost always met with construction workers during breaks and after work, the value of the time spent by workers participating in program activities was not estimated.

The time spent by program coordinators supervising the interventions was valued using their salary and benefits. Other staff from the labor union and HCMC AIDS Committee also assisted in managing the interventions, and their time was valued similarly using their salary and benefits. Additional resources that were used in the interventions include venues for meetings, stationery, printing, materials, transportation, and refreshments.

\section{Data analysis}

Some of the assumptions that were made in the analysis included the following:

- Because the drop-out rate for both peer educators and health communicators was high and new trainings would have to be held every year, the researchers chose to treat the costs of training of PEs and HCs as recurrent and not annualize them.

- Training for program coordinators would last for more than one year, and these costs were annualized.

- In the health communication intervention, a second batch of HCs $(n=29)$ was added to the intervention, but they did not receive training at this time since they had already been trained. The cost of training these HCs was estimated and added to the total costs of the HC intervention.

- Because the involvement of international consultants in designing, training sessions, and implementation was considered to be a one-time event and would not be needed in a scale-up of the peer education intervention, the value of their time both in training and implementation was substituted with local consultants' rates. 
The costs of the interventions were estimated over the 12 months of the intervention. The rationale for this is that changes occurred in both interventions during the 12 months. The peer education intervention was less intensive during the second six months because the peer educators often moved to new construction sites. At the same time, the health communication program was intensified during the second six months. In order to capture the full effect of both interventions, an analysis of the full period was considered most appropriate.

The results of the study indicated that HIV risk behavior measures, such as condom use, changed relatively little during the period due to low reported levels of sexual activity. Thus, rather than using outcome measures such as change in condom use, this analysis uses measures of output on exposure to intervention activities. Specifically, the number of construction workers reporting contact with a PE or HC during the last six months on surveys was used as the output measure. While the number of persons that the PEs and HCs report having reached was also available via monitoring forms, reports by the workers themselves were deemed to be more reliable.

\section{Results of cost study}

The total costs of the two interventions during the 12 months from July 2001 to June 2002 were $\$ 15,678$ and $\$ 12,455$, respectively, for peer education and health communication (see Table 6). The largest cost component was the payment of stipends to the PEs and the HCs to recompense them for their time participating in the interventions. Most of the costs for the intervention were monetary, requiring a financial outlay. However, some of the resources were donated (condoms and brochures by the National AIDS Control Program) and some of the staff time paid for by local institutions.

The peer education intervention cost approximately $\$ 3,000$ (26 percent) more than the health communication intervention. More funds were spent on training activities in the peer education program because more training was conducted and more peer educators were trained. In addition, this training included the topic of managing the peer education program, while this was not done for the health communication intervention, since it was ongoing. The supervision and involvement of the local Vietnamese institutions in implementation of the peer education intervention was also higher.

The cost of conducting the interventions with and without distribution of condoms was calculated since an alternative option for the intervention would be to direct workers to buy the condoms elsewhere if they were costly to the intervention. Table 6 indicates that the cost of the condoms was only a small component of the overall cost (4 percent and 2 percent of peer education and health communicator programs, respectively). 
Table 6 Total costs of peer education and health communication interventions, July 2001-June 2002 (in dong; 15,000 dong per 1 dollar)

\begin{tabular}{|c|c|c|c|c|}
\hline \multirow[t]{2}{*}{ Cost component } & \multicolumn{2}{|c|}{ Peer Education } & \multicolumn{2}{|c|}{ Health Communication } \\
\hline & $\mathbf{M}^{*}$ & $\mathbf{N M}^{*}$ & M & NM \\
\hline \multicolumn{5}{|l|}{ Start-up Training } \\
\hline Time of trainers and trainees & $33,799,806$ & & 14,544 & \\
\hline Training materials and venue & $24,082,575$ & & 13,674 & \\
\hline $\begin{array}{l}\text { Extra training for } \mathrm{PE} \\
\text { program coordinators }\end{array}$ & $1,660,445$ & & \multicolumn{2}{|c|}{ Not Applicable } \\
\hline $\begin{array}{l}\text { Management "motivation" } \\
\text { materials for PE program }\end{array}$ & $1,220,130$ & & \multicolumn{2}{|c|}{ Not Applicable } \\
\hline Subtotal: training & $60,762,956$ & & 28,219 & \\
\hline \multicolumn{5}{|l|}{ Service Delivery } \\
\hline Time of PE or $\mathrm{HC}$ & $110,100,000$ & & 115,665 & \\
\hline Supervision & $20,611,432$ & & 13,959 & \\
\hline $\begin{array}{l}\text { Time of other staff in } \\
\text { implementation }\end{array}$ & & $2,031,454$ & 1,378 & \\
\hline $\begin{array}{l}\text { Photocopying and other } \\
\text { materials }\end{array}$ & $17,774,904$ & & 9,246 & \\
\hline Condoms & & $8,495,000$ & & $2,878,800$ \\
\hline Brochures & & $15,394,400$ & & $15,470,400$ \\
\hline $\begin{array}{l}\text { Subtotal: service delivery } \\
\text { with cost of condoms }\end{array}$ & \multicolumn{2}{|c|}{$174,407,190$} & \multicolumn{2}{|c|}{$158,598,443$} \\
\hline $\begin{array}{l}\text { Subtotal: service delivery } \\
\text { without cost of condoms }\end{array}$ & \multicolumn{2}{|c|}{$165,912,190$} & \multicolumn{2}{|c|}{$155,719,643$} \\
\hline TOTAL COSTS with condoms & \multicolumn{2}{|c|}{$\begin{array}{l}235,170,146 \text { dong } \\
\text { (US } \$ 15,678)\end{array}$} & \multicolumn{2}{|c|}{$\begin{array}{l}\text { 186,817,486 dong } \\
\text { (US } \$ 12,455)\end{array}$} \\
\hline $\begin{array}{l}\text { TOTAL COSTS without } \\
\text { condoms }\end{array}$ & \multicolumn{2}{|c|}{$\begin{array}{l}226,675,146 \text { dong } \\
\text { (US } \$ 15,112)\end{array}$} & \multicolumn{2}{|c|}{$\begin{array}{l}\text { 183,938,686 dong } \\
\text { (US\$ } 12,263)\end{array}$} \\
\hline
\end{tabular}

*Note: $\mathrm{M}=$ monetary costs, $\mathrm{NM}=$ nonmonetary costs

\section{Outputs in the two interventions}

As reported above, the researchers administered surveys to construction workers at three points in time: baseline, and six months and 12 months after the interventions began. At six months, 74 percent of workers in PE sites $(n=751)$ and 57 percent at HC sites $(n=505)$ reported contact with the program over the last six months. After 12 months, fewer workers reported having been contacted over the prior six months: 61 percent at PE sites $(n=363)$ and 45 percent at HC sites $(n=$ 211), respectively. Extrapolating from the sampling strategy, the number of workers estimated to be at construction sites with PEs and HCs after 12 months were 820 and 740 workers, respectively. Because the survey did not include workers from earlier construction sites, however, it is likely that the results underestimated the number of workers contacted. 


\section{Cost per contact or worker reached}

When the productivity of the two interventions after 12 months was analyzed, the cost of contacting a worker was found to be lower in the peer education intervention than the health communication intervention (see Table 7). This is because even though total costs of the peer education program were higher, the higher productivity of this intervention, as reported by workers, resulted in a 16 percent lower cost per worker reached. This result was obtained even though the peer education intervention used more materials and secretarial support in the first six months to get the intervention under way than did the $\mathrm{HC}$ intervention, which was already under way.

\section{Table 7 Cost per worker contacted in last six months, by type of intervention,} July 2001-June 2002

\begin{tabular}{lcc}
\hline & Peer Education & Health Communication \\
\hline $\begin{array}{l}\text { No. of workers contacted by } \\
\text { PE or HC (estimated) }\end{array}$ & 500 & 333 \\
Cost per worker contacted & 470,340 dong & 561,013 dong \\
& (US\$ 31.36) & (US\$ 37.40)
\end{tabular}

Note: The number of workers estimated as contacted by PE or $\mathrm{HC}$ is calculated by multiplying the percentage of workers in the survey that reported having been contacted, by the total number of workers.

\section{Cost of replicating the peer education intervention}

In Table 8, the costs of replicating the peer education intervention at an additional six sites have been simulated. The number of peer educators and health communicators is assumed to be the same as in the initial intervention. Some of the assumptions that were made in the simulation are the following:

- The training of Labor Union and HCMC AIDS Committee program managers would not be needed.

- Only two-thirds of the training materials would be required, assuming that some of the materials produced for the initial trainings could be reused in later ones.

- Less time would be required of other staff (two-thirds) in implementation since the intervention has now been tested and requires less supervision.

- Half of the photocopying and other materials for implementation would be required, since some can be reused in the scaled-up interventions.

The total costs of the peer education intervention would be US\$12,648, while the monetary costs to the program would be lower-US $\$ 11,991$. If the same number of contacts with workers in the new sites takes place, the cost per worker contacted for the peer education intervention would be reduced from US\$31.36 to US\$25.30. Other scenarios that would reduce the cost per worker reached include increasing the number of persons trained at each session, increasing the number of 


\section{Hgrizons}

construction sites where the intervention is offered, and asking workers to purchase their own condoms.

\begin{tabular}{|c|c|c|}
\hline \multirow[t]{2}{*}{ Cost component } & \multicolumn{2}{|c|}{ Peer Education } \\
\hline & $\mathbf{M}^{*}$ & $\mathrm{NM}^{*}$ \\
\hline \multicolumn{3}{|l|}{ Training } \\
\hline Time of trainers and trainees & $15,066,946$ & \\
\hline Training materials and venue & $16,063,077$ & \\
\hline Subtotal: training & $31,130,023$ & \\
\hline \multicolumn{3}{|l|}{ Service delivery } \\
\hline Time of PEs & $110,100,000$ & \\
\hline Supervision & $13,747,000$ & \\
\hline Time of other staff in implementation & & $1,378,734$ \\
\hline Stationery and other materials & $8,887,000$ & \\
\hline Condoms & & $8,495,000$ \\
\hline Brochures & $16,000,000$ & \\
\hline Subtotal: service delivery & $158,584,805$ & \\
\hline Total & $\begin{array}{r}179,864,848 \\
\text { (US } \$ 11,991)\end{array}$ & $\begin{array}{l}\mathbf{9 , 8 4 9 , 9 8 0} \\
\text { (US } \$ 657 \text { ) }\end{array}$ \\
\hline
\end{tabular}

*Note: $\mathrm{M}=$ monetary costs, $\mathrm{NM}=$ nonmonetary costs

\section{Cost compared with other HIV prevention programs}

To compare whether the cost per construction worker contacted was similar to that found in other studies, the unit cost was compared with recent findings from other costing studies of HIV prevention interventions (Creese et al. 2002; Kumaranayake et al. 2000). While methodologies and geographical locations of the individual studies vary, these reports are among very few publications that are currently available that describe a costing analysis for HIV prevention interventions. The results indicate that the cost of reaching a mobile construction worker (i.e., US\$31.36) falls within the range of those found in these other preventive interventions. A voluntary counseling and testing program in Kenya, for example, found that the cost of reaching a client was US\$28.76. A peer education program in Cameroon found that the cost of reaching a person in the target population was US\$31.70.

The costing analysis of the study demonstrates that although the peer education program is somewhat more costly overall, given the success of the intervention in reaching a higher percentage of workers with activities, the cost is lower per worker reached, as compared to the health communicator intervention. Furthermore, the current cost is comparable to costs from HIV prevention programs conducted in other settings, and it would be substantially less expensive to replicate the PE intervention in additional sites. 


\section{Dissemination Workshop and Future Plans}

A workshop to disseminate and discuss key study findings was held with approximately 90 people in HCMC on 6 December 2002. In additional to sharing lessons learned, participants discussed the possibility of scaling-up workplace HIV/AIDS prevention activities for migrant construction workers in HCMC and in other parts of Vietnam. The research and intervention team, from the Horizons Program, Population Council/Vietnam, the College of Social Sciences and Humanities of HCMC National University, the HCMC AIDS Committee, and the HCMC Labor Union, led the discussion. Companies that participated in the intervention, as well as peer educators and health communicators, also attended the workshop. Representatives from Ford Foundation, the funder of the intervention component, and USAID, the funder of the research component, also attended.

A wide range of local and national government bodies, and international and local organizations working in the field of HIV/AIDS, were also represented. From the national government in Vietnam, there were representatives from the National AIDS Standing Bureau (NASB), Vietnam General Federation of Labor Unions (VGFLU), and the Vietnam Chamber of Commerce and Industry (VCCI). From city government, there were representatives from all 22 district AIDS divisions, the Department of Labor, Invalid and Social Affairs (DOLISA), HCMC Youth Union, HCMC Youth Volunteer Force, and HCMC Women's Union. International organizations in attendance included Care International, Australian Red Cross, SCF-UK, Medecins du Monde France, Medecins du Monde Canada, FASID, Pasteur Institut Paris, ANRS France, and Action Aid.

The HCMC AIDS Committee presented their future plans for the utilization of the research findings as follows:

- Develop a strategy for scaling-up the peer education model for migrant construction workers in Ho Chi Minh City.

Given that, based on the study findings, the peer education program is the better option to reach migrant construction workers, the committee intends to support the replication and expansion of this model. To do that, the HCMC AIDS Committee will work with the HCMC Labor Union and other relevant organizations to expand this peer education program to other construction sites in the city, and will provide technical assistance to construction companies who are willing to adopt the management motivation and/or peer education components of the program.

- For construction companies that are not yet ready to participate in a peer education program, continue contacting their workers through health communicators.

Although the peer education program appears most effective, and is less costly per worker reached, than the health communication program, it takes time to set up and requires management support. This may be not possible for some construction companies at this time. Therefore, since the health communicator program was shown to be effective on a number of 


\section{Hgrizons}

key measures, the AIDS Committee will continue to use the health communication program as an alternate program to target construction workers in these companies.

- Undertake additional dissemination of the study findings to construction companies.

To replicate the peer education model for migrant construction workers on a larger scale, it is necessary to work with construction companies. Dissemination of the research findings to construction companies will be an essential step to get them involved and adopt the peer education program for their workers.

- Disseminate the results of the evaluation nationally.

Lessons learned from this study are useful not only for Ho Chi Minh City but also for other regions of the country. Dissemination of research findings will be the first step in expanding the peer education model for migrant construction workers outside the borders of HCMC.

- Coordinate with the National AIDS Standing Bureau to implement the peer education and management motivation program for migrant construction workers in other provinces.

Dr. Le Truong Giang, standing vice-chairman of the HCMC AIDS Committee, indicated that this model would be useful beyond HCMC. Now that the results are available, this model should be replicated in other cities. The AIDS Committee of HCMC plans to coordinate with the NASB to implement the peer education program for migrant construction workers in other provinces where possible.

- Seek additional funding to expand and improve the management motivation and peer education program.

Given that internal resources for HIV/AIDS programs are limited, it is necessary to obtain additional financial support to maximize the coverage of the management motivation and peer education program in HCMC and in Vietnam. The AIDS Committee will seek further resources to support these programs. 


\section{Conclusions and Recommendations}

Findings about the impact of the program on workers indicate that the peer education program reached a higher proportion of the workers than the health communicator program. HIV-related knowledge, STI awareness, condom efficacy, life skills, and HIV/AIDS risk perception significantly increased in both the $\mathrm{PE}$ and $\mathrm{HC}$ arms, but often more so among workers exposed to the PE program. HIV-related stigma decreased significantly for both arms, but more so for workers exposed to the peer education program. Norms related to appropriate sexual behavior significantly changed to support risk reduction norms in the PE sites only. Evidence also suggests a diffusion effect in the PE intervention sites, given that workers at the PE sites who were not directly exposed to $\mathrm{PE}$ activities also reported positive change in many of these variables. This change was not found for workers not exposed to $\mathrm{HC}$ activities at the $\mathrm{HC}$ sites. These results are important for relatively low-prevalence environments such as Vietnam because such factors as increased efficacy regarding condom use and norms in support of risk reduction have been shown to be important precursors to behavioral risk reduction.

Reported risky sexual behavior in the surveys was quite low in this population, so conclusions about the impact of the programs on sexual risk behavior are limited. There is some evidencesuch as an increase of condom use with a non-marital sexual partner - that suggests an impact in that area. Furthermore, the qualitative data suggest that there was both more HIV risk behavior on the part of workers than what was found in the close-ended surveys, and reductions in risk behavior and increases in safer sex practices, particularly among workers exposed to the peer education intervention. These findings highlight the importance of triangulating information gathered on sensitive issues from multiple sources and with varied strategies.

Although at baseline PEs had poorer knowledge of HIV/AIDS than HCs and were less comfortable discussing sensitive topics, after training and six months of experience in the field, PEs were more comfortable discussing sensitive topics than were HCs and had equivalent levels of knowledge. A somewhat lower proportion of PEs than HCs dropped out of the program. Therefore, many of the potential disadvantages of using PEs expressed at the beginning of the intervention, such as concern that the construction workers might not be capable PEs or might drop out in greater numbers, were not supported by the data. Moreover, study findings indicate that the peer educators did continue to implement activities after moving from their original site to other work sites, which supports the original supposition that a peer education strategy might be advantageous for a mobile workforce.

The cost per worker reached by the PE program was lower than that of the HC program. Furthermore, the costs were comparable to costs from HIV prevention programs conducted in other settings, and it would be substantially less expensive to replicate the PE intervention in additional sites. This finding is of great relevance both for local authorities who are determining which program to take forward and scale up, and for construction companies that are considering implementing a peer education program with their own funds. 


\section{Hgrizons}

An important part of the PE program was involving company management, since PE programs require permission from authorities to train their workers and allow them time to engage in $\mathrm{PE}$ activities. Findings from construction company managers indicate that their support of workplace HIV/AIDS programs was motivated by multiple factors. These range from concerns about the wellbeing of their workers to the desire to reduce stigma in the workplace. Having a reputable organization such as the labor union address concerns about costs and time spent appears to be an important part of a successful strategy to get management on board.

For the reasons provided above, the results of the evaluation suggest that the peer education program is the better option in this setting. Local authorities have determined that they would focus their efforts on the peer education program, while maintaining a cadre of health communicators for companies that are unable or unwilling to implement a peer education program. To strengthen the PE program, however, findings indicate that peer educators should be trained regularly when new sites are included as part of the program, to maintain an appropriate ratio between peer educators and workers. Also, the role of the peer coordinator was an important one and should be continued, to support the peer educators and foster good relations with the management. Finally, the role that gender dynamics may have played in the ability of the HCs to do their jobs successfully, and remain in the program, should be further investigated.

Gaining the support of management is key. Since an important difference between the two interventions may have been the outreach made to engage management, a management motivation component should be included in the HC program as well. Management endorsement of their work could potentially increase the HC's effectiveness. Local authorities indicated that the management motivation component was deemed sufficiently successful to recommend its use in all types of local workplace programs.

While both the $\mathrm{PE}$ and $\mathrm{HC}$ programs had a positive impact on workers, the PE program appears to have a number of advantages over the HC program for this type of work environment. The PE program was less costly per worker reached; PEs fared as well or better than HCs in terms of knowledge, motivation, and dropout rates; more workers were reached by the PE program; and there was a diffusion effect to workers not directly exposed to activities. Management support appears to play an important role and should be encouraged in all types of workplace interventions. These findings should help inform future efforts to scale up and improve the sustainability of these programs in Vietnam, as well as provide global lessons regarding workplace HIV/AIDS interventions. 


\section{References}

Bandura, A. 1986. Social Foundations of Thought and Action: A Social Cognitive Theory. Englewood Cliffs, New Jersey, Prentice-Hall.

Chaiyapet, S. et al. 1996. Friends Tell Friends: A peer-based HIV/AIDS curriculum for blue collar and white collar workers. Bangkok: Program on AIDS, Thai Red Cross Society.

Chung, A. et al. 1998. "HIV epidemiologic situation in Vietnam: A review of available data." AIDS 12 (suppl): S43-S49.

Chung, A. and Thomas T. Kane, eds. 2001. HIV/AIDS Behavioral Surveillance Survey: Vietnam 2000. Hanoi: Family Health International and National AIDS Standing Bureau.

Creese, A. et al. 2002. "Cost-effectiveness of HIV/AIDS interventions in Africa: a systematic review of the evidence." The Lancet 359 (9318): 1635-42.

Kumaranayake, L. et al. 2000. "Economic costs of HIV/AIDS prevention activities in sub-Saharan Africa." AIDS 14 (suppl): 239-252.

Hoa, D.D. and Trinh Khac Tham. 1999. Migration in Vietnam. Department of Permanent Agriculture and Permanent Settlement/The Ministry of Agriculture and Rural Development and UNDP. Hanoi: Agricultural Publishing House

National AIDS Standing Bureau (2001). HIV/AIDS Country Profiles. Hanoi: NASB.

National AIDS Standing Bureau (2002). HIV/AIDS Country Profiles. Hanoi: NASB. 


\section{Hgrizons}

Horizons is a global operations research program designed to:

- Identify and test potential strategies to improve HIVIAIDS prevention, care, and support programs and service delivery.

- Disseminate best practices and utilize findings with a view toward scaling up successful interventions.

\section{(2) Population Council}

Horizons is implemented by the Population Council in collaboration with

- International Center for Research on Women (ICRW)

- International HIVIAIDS Alliance

- Program for Appropriate Technology in Health (PATH)

- Tulane University

- Family Health International (FHI)

- Johns Hopkins University

For more information, please contact:

Horizons Program, Communications Unit 4301 Connecticut Avenue, NW Suite 280 Washington, DC 20008 USA

Tel: 202-237-9400

Fax: 202-237-8410

Email: horizons@pcdc.org www.popcouncil.org/horizons 